Utah State University

DigitalCommons@USU

\title{
Examination of the Relationship Between Perfectionism and Religiosity as Mediated by Psychological Inflexibility
}

Jesse M. Crosby

Utah State University

Follow this and additional works at: https://digitalcommons.usu.edu/etd

Part of the Personality and Social Contexts Commons

\section{Recommended Citation}

Crosby, Jesse M., "Examination of the Relationship Between Perfectionism and Religiosity as Mediated by Psychological Inflexibility" (2010). All Graduate Theses and Dissertations. 581.

https://digitalcommons.usu.edu/etd/581

This Thesis is brought to you for free and open access by the Graduate Studies at DigitalCommons@USU. It has been accepted for inclusion in All Graduate Theses and Dissertations by an authorized administrator of DigitalCommons@USU. For more information, please contact digitalcommons@usu.edu.

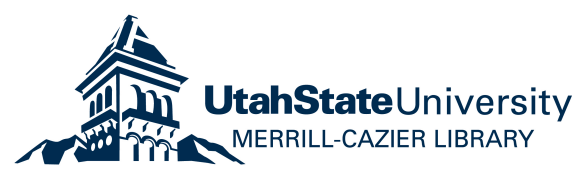


EXAMINATION OF THE RELATIONSHIP BETWEEN PERFECTIONISM AND

RELIGIOSITY AS MEDIATED BY PSYCHOLOGICAL INFLEXIBILITY

by

\author{
Jesse M. Crosby \\ A thesis submitted in partial fulfillment \\ of the requirements for the degree \\ of \\ MASTER OF SCIENCE \\ in
}

Psychology

Approved:

Scott C. Bates, Ph.D.

Renee V. Galliher, Ph.D.

Major Professor

Committee Member

Michael P. Twohig, Ph.D.

Byron R. Burnham, Ed.D.

Committee Member

Dean of Graduate Studies

\title{
UTAH STATE UNIVERSITY
}

Logan, Utah 
Copyright (C) Jesse M. Crosby 2010

All Rights Reserved 


\author{
ABSTRACT \\ Examination of the Relationship Between Perfectionism and Religiosity \\ as Mediated by Psychological Inflexibility \\ by \\ Jesse M. Crosby, Master of Science \\ Utah State University, 2010
}

Major Professor: Scott C. Bates, Ph.D.

Department: Psychology

The relationship between perfectionism and religiosity is clarified when the adaptive and maladaptive dimensions of both constructs are compared. Literature in both areas implicates the idea of a rigid and inflexible personality style as a possible mediator in the relationship. This investigation examined the relationship of perfectionism and religiosity, using adaptive and maladaptive dimensions, as mediated by psychological inflexibility.

Measures of perfectionism, religiosity, and psychological inflexibility were given to 376 undergraduate college students in an anonymous online survey. Adaptive perfectionism was found to be significantly correlated with adaptive religiosity. Maladaptive perfectionism was found to be significantly correlated with maladaptive religiosity. Psychological inflexibility was found to be significantly correlated with the maladaptive dimensions of both perfectionism and religiosity. It was also shown to 
mediate the relationship between maladaptive religiosity and maladaptive perfectionism using the test of mediation proposed by Baron and Kenny. Implications and future directions are discussed. 


\section{ACKNOWLEDGMENTS}

I would like to acknowledge the support and encouragement of my committee chair, Scott C. Bates. I would also like to thank my committee members, Renee V. Galliher and Michael P. Twohig, for their help in shaping this project. The faculty and staff of the Department of Psychology and School of Graduate Studies at Utah State University were helpful and kind as I completed this project. Special thanks are also due to those who assisted in recruiting participants and collecting data. Thanks to Tom and Ray Magliozzi for their encouragement in my academic pursuits. Finally, I am grateful to my family for their love and support while I have worked on this project.

Jesse M. Crosby 


\section{CONTENTS}

ABSTRACT.

iii

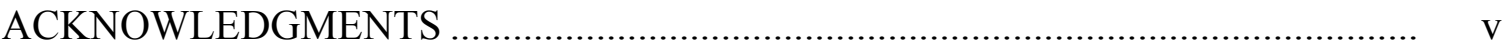

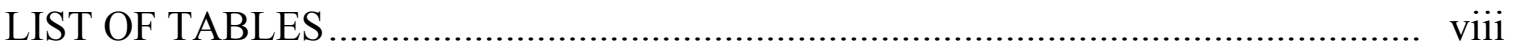

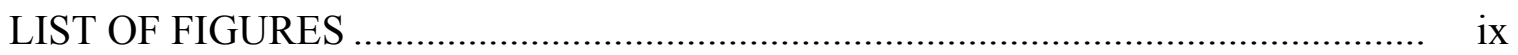

\section{CHAPTER}

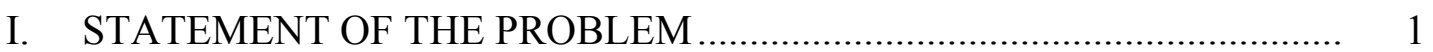

II. REVIEW OF THE LITERATURE ....................................................... 4

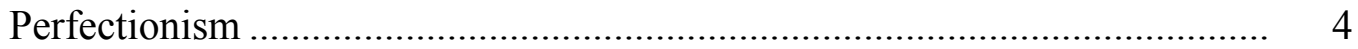

Religiosity .................................................................................. 15

Perfectionism and Religiosity .......................................................... 19

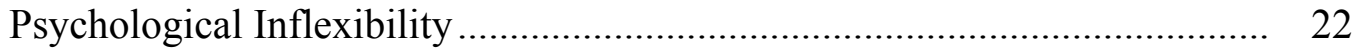

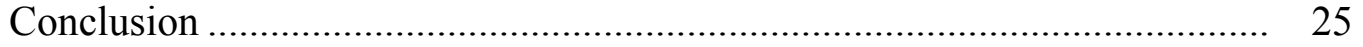

Research Questions and Hypotheses .................................................. 26

III. METHOD …............................................................................... 31

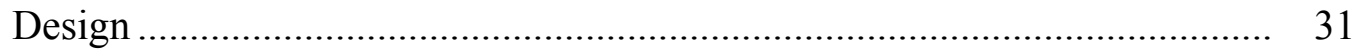

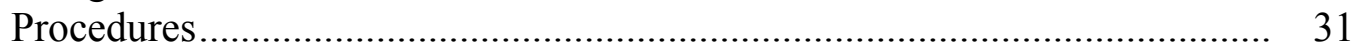

Participants ................................................................................... 31

Measures .................................................................................. 32

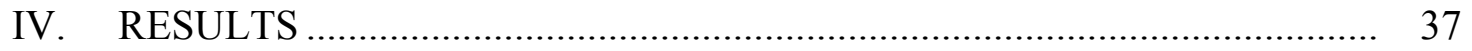

Perfectionism and Religiosity ........................................................... 37

Psychological Inflexibility .............................................................. 39

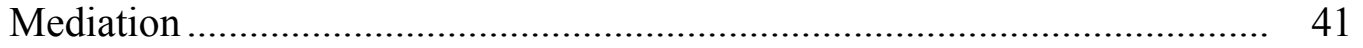

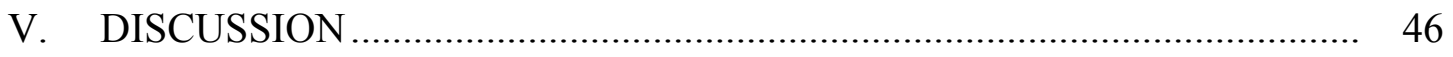

Perfectionism and Religiosity .......................................................... 46

Psychological Inflexibility ............................................................. 48

Mediation ..................................................................................... 50 
Implications of the Results............................................................. 52

Limitations and Future Directions ................................................... 56

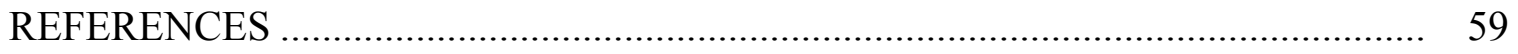

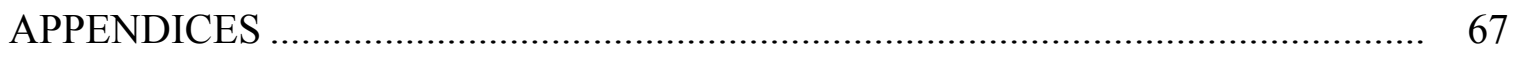

Appendix A: Measures ..................................................................... 68

Appendix B: Recruiting Materials................................................... 73

Appendix C: Informed Consent..................................................... 75 


\section{LIST OF TABLES}

$\begin{array}{lll}\text { Table Page } & \end{array}$

1. Demographic Characteristics ....................................................................... 33

2. Descriptive Statistics for Measures of Perfectionism, Religious Orientation, and Psychological Inflexibility .................................................................... 37

3. Correlations Between Perfectionism Dimensions and Religious Orientation ... 38

4. Test for Mediation: Psychological Inflexibility as a Mediator Between External Religious Orientation and Discrepancy Perfectionism ...................... 44 


\section{LIST OF FIGURES}

$\begin{array}{lll}\text { Figure } & \text { Page }\end{array}$

1. Psychological inflexibility as a mediator between external religiosity and

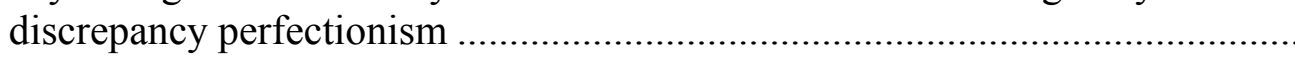




\section{CHAPTER I}

\section{STATEMENT OF THE PROBLEM}

Perfection is often expected and encouraged, but this striving for perfection can sometimes become problematic or even pathological. Perfectionism is generally defined by the setting of unreasonably high standards and the resulting self-criticism when those standards are not reached (Burns, 1980). It can lead to a host of negative outcomes including procrastination (Flett, Blankstein, Hewitt, \& Koledin, 1992), stress (Hewitt \& Flett, 2002), shame and guilt (Fedewa, Burns, \& Gomez, 2005), low self-esteem (Ashby \& Rice, 2002), and interpersonal problems (Flett, Hewitt, Shapiro, \& Rayman, 2001). It has also been associated with eating disorders (Goldner, Cockell, \& Srikameswaran, 2002), obsessive-compulsive disorder (Shafran \& Mansell, 2001), depression (Hewitt \& Flett, 1991a), social anxiety (Alden, Ryder, \& Mellings, 2002), and suicide (Hewitt, Flett, \& Weber, 1994).

Research in perfectionism has addressed the development of the construct, the association of perfectionism with negative outcomes, and examining perfectionism in the context of environments characterized by high standards. These high-standard environments include sports and exercise (Flett \& Hewitt, 2005), education (Parker, 2002), professional achievement (Henning, Ey, \& Shaw, 1998), and religion (Ashby \& Huffman, 1999).

The connection between perfectionism and religiosity seems likely because of their shared high standards. Research in both fields has also identified the importance of accounting for adaptive versus maladaptive dimensions of the constructs (Allport \& Ross, 
1967; Slade \& Owens, 1998). When the constructs are compared using adaptive and maladaptive subdimensions, the relationship between perfectionism and religiosity can best be described by accounting for the subdimensions of the construct. Specifically, it appears that the adaptive and maladaptive distinction in both religiosity and perfectionism helps explain how religious standards in well-meaning individuals can be associated with negative outcomes (i.e., maladaptive perfectionism). This leads to the primary research question at hand in this investigation that looks at why this established relationship exists using a mediational variable (Baron \& Kenny, 1986).

The idea of a mediational variable that could explain why this relationship exists emerged from the review of the literature in which the rigid and inflexible personality style was regularly implicated in the literature examining both perfectionism and religiosity. Maladaptive perfectionism has been attributed to an intolerant superego (Freud, 1961), all-or-nothing rigidity (Beck, 1976), inflexible high standards (Hamachek, 1978), and rigidly holding to standards (Hewitt \& Flett, 1991b). Similarly, maladaptive religiosity has been attributed to indiscriminate and inflexible responses to religious teachings (Allport \& Ross, 1967). Because maladaptive perfectionism and religiosity are correlationally linked, the question turns to causation, and the implication of an underlying psychological inflexibility, as shown in the literature, suggested that this relationship might best be explained using psychological inflexibility as a mediator.

Psychological inflexibility, a construct of the model of psychopathology described by acceptance and commitment therapy (ACT; Hayes, Strosahl, \& Wilson, 1999), refers to the rigid, narrow, and inflexible style of interacting with unwanted private experiences 
(e.g., thoughts, feelings, bodily sensations). Psychological inflexibility has been associated with a variety of pathological conditions (Hayes, Luoma, Bond, Masuda, \& Lillis, 2006), and it has also been suggested as the mechanism by which some individuals, when placed in similar contexts, will manifest pathology while others will not (Olatunji, Forsyth, \& Feldner, 2007).

The purpose of this investigation was to build on the existing knowledge of an established relationship between perfectionism and religiosity by looking closely at the subdimensions of the constructs and then examining the role of how those relationships are mediated by psychological inflexibility. A literature review was conducted to answer the following research questions and develop an appropriate set of questions for this investigation.

1. What is the relationship between the adaptive and maladaptive dimensions of perfectionism and the adaptive and maladaptive dimensions of religiosity?

2. What is the relationship between psychological inflexibility and the adaptive and maladaptive dimensions of perfectionism and religiosity?

3. If the established relationships from the literature hold true in this investigation, does psychological inflexibility mediate those relationships? 
CHAPTER II

REVIEW OF THE LITERATURE

\section{Perfectionism}

\section{The Emergence of the Construct}

The psychological construct of perfectionism was addressed in early psychological theories of personality and psychopathology. Perfectionism was described as obsessional neurosis (Freud, 1959), and characterized by exacting standards, meticulous living, and unfulfilled expectations (Horney, 1950). Perfectionism was designated as a component of obsessive-compulsive behavior (Branfman \& Bergler, 1955), and a distinction emerged between unrealistic expectations for the self and unrealistic expectations for others. The construct was characterized as irrational and dysfunctional, highlighted by the catastrophic nature of failing to meet unrealistic standards (Ellis, 1962), and the all-or-nothing attitude in which falling short of expectations is interpreted as a failure (Beck, 1976).

The idea of adaptive and maladaptive forms of perfectionism emerged as the striving for perfection and superiority was portrayed as a basic human drive necessary for adaptation, but this striving for perfection could also take on pathological properties if the perfection of the self took precedence over social interest (Adler, 1956). Maladaptive perfectionism was characterized by inflexible high standards across all situations in contrast to a more adaptive perfectionism in which standards could be adjusted according to the situation. This distinction is clarified by the source of the motivation to perform; a 
maladaptive fear of failure compared to an adaptive desire for improvement (Hamachek, 1978). It is important to separate the healthy pursuit of excellence, quality work, and true accomplishment from the compulsive striving and self-defeating drive to meet impossible expectations (Burns 1980). While some theorists have made the distinction between adaptive and maladaptive perfectionism, the use of the construct has also been carefully reserved for the maladaptive features of perfectionism. This includes persistent dissatisfaction with performance, no matter how good (Hollender, 1965), and the designation of perfectionism as an underlying feature of a variety of psychological disorders (Pacht, 1984).

Perfectionism has been associated with several types of psychopathology including eating disorders, obsessive-compulsive disorder (OCD), depression, social anxiety, and suicide. Eating disorders have been associated with perfectionistic features including excessive compliance, overconscientiousness, approval seeking, a false self, the need for control, worry about negative evaluations, reward dependence, dichotomous reasoning, overgeneralization of negative information, and magnification of negative information. Phenomenologically, perfectionism is believed to be part of anorexia nervosa (Shafran \& Mansell, 2001). Perfectionism has been identified as one of the six domains of OCD (Frost \& DiBartolo, 2002), and both clinical and nonclinical populations have demonstrated significantly higher levels of perfectionism (Frost \& Steketee, 1997). Higher levels of depression have been found to be associated with higher levels of self-oriented and socially prescribed perfectionism from the Hewitt and Flett Multidimensional Perfectionism Scale (MPS; Hewitt \& Flett, 1991a). Clinical subjects 
with social phobia have been found to display greater symptom severity (Juster et al., 1996). Suicide ideation has been found to interact with life stress to predict more severe suicidal ideation (Hewitt et al., 1994). Perfectionism has also been associated with several negative outcomes such as poor physical health, procrastination, interpersonal problems, shame and guilt, stress, and low self-esteem (Ashby \& Rice, 2002; Fedewa et al., 2005; Flett et al., 1992, 2001; Hewitt \& Flett, 2002; Lundh, Broman, Hetta, \& Saboonchi, 1994; Saboonchi \& Lundh, 2003).

\section{Theoretical Debate}

The identification of the negative consequences of perfectionism lead to increased interest and the need for a better understanding perfectionism. In response to this need, two multidimensional approaches to maladaptive perfectionism were developed around the same time: the MPS (Frost, Marten, Lahart, \& Rosenblate, 1990) and another scale of the same name by Hewitt and Flett (MPS; 1991b). The Frost and colleagues conceptualization focused on the intrapersonal dimensions of perfectionism while the Hewitt and Flett conceptualization addressed the interpersonal dimensions (Parker \& Adkins, 1995).

The multidimensional approach of the Frost and colleagues (1990) theory was derived from the previous literature on perfectionism. A number of important dimensions were consistently identified: (a) excessively high standards; (b) the level of concern over mistakes; (c) a sense of doubt about the quality of one's performance; (d) concern over parent's expectations and evaluations; and (e) an overemphasis on precision, order, and organization. This approach, thus, identifies an overall perfectionism as well as 
subdimensions that may vary between individuals (Frost, Heimberg, Holt, Mattia, \& Neubauer, 1993). This multidimensional perfectionism has been associated with suicidal preoccupation, sexual dysfunction, and chronic fatigue (Enns \& Cox, 2002).

The Hewitt and Flett conceptualization added interpersonal dimensions to what had previously been a unidimensional self-directed approach (Hewitt \& Flett, 1991b). Citing research on the public versus private self and the intraindividual and interindividual components of the psychiatric disorders, it was argued that perfectionism has both personal and social components. As such, the conceptualization is made up of three dimensions: (a) self-oriented perfectionism, (b) other-oriented perfectionism, and (c) socially prescribed perfectionism, each of which is characterized not by differences in behaviors or cognitions but in the object of the perfectionism. Self-oriented perfectionism describes the exacting standards and excessive critical evaluation of one's performance. Other-oriented perfectionism describes the same high standards and criticism directed at others. Socially prescribed perfectionism describes the perceptions that significant others have unrealistic standards for them, are overly critical, and pressure them to be perfect.

This multidimensional approach has been used to identify the relationship of perfectionism to psychopathological conditions including the anxiety, somatoform, mood, substance, and psychotic disorders. The research has also supported the multidimensional concept as the findings varied as a function of the dimension of perfectionism (Hewitt \& Flett, 1991b).

There are differences between the two multidimensional conceptualizations, especially the interpersonal focus of Hewitt and Flett (Parker \& Adkins, 1995), and each 
scale taps into some unique factors, but there is also significant conceptual overlap (Enns \& Cox, 2002; Frost et al., 1993). While both multidimensional theories of perfectionism purport to be concerned with the maladaptive features of perfectionism, it has been argued that they also capture some adaptive features. For example, the organization dimension in the Frost et al. conceptualization is purported to tap into adaptive characteristics (Enns \& Cox, 2002). Factor analysis of the subscales of the two multidimensional scales has resulted in two factors: positive striving and maladaptive evaluation concerns (Frost et al., 1993). The self-oriented dimension of the Hewitt and Flett MPS has been shown to be positively correlated with the adaptive variables of achievement motivation and self-control (Klibert, Langhinrichsen-Rohling, \& Saito, 2005). It is clear that the scales do focus on the maladaptive and pathological features of perfectionism, but a growing body of research is consistent with the early theory that there are some positive aspects of perfectionism.

The distinction between maladaptive and adaptive perfectionism was identified by some of the early writers in perfectionism based on clinical experience and anecdotal evidence (Burns 1980; Hamachek, 1978). This distinction has been supported by the multidimensional research and studies designed to test the positive and negative perfectionism theory. The Dual Process Model of Perfectionism made a distinction between the pursuit of success, excellence, approval, and satisfaction; and the avoidance of failure, mediocrity, disapproval, and dissatisfaction (Slade \& Owens, 1998). Perfectionism was conceptualized in terms of perceived consequences, and this conceptualization was modeled after the behavioral principles of positive and negative 
reinforcement (Terry-Short, Owens, Slade, \& Dewey, 1995). There was evidence that marathon runners displayed similar levels of perfectionism as those seen in individuals with eating disorders, but levels of dissatisfaction that were comparable to normal controls. This suggested that the consequences of perfectionism play an important role in the form and function of the behavior, and the construct could be defined in terms of both negative and positive outcomes. Factor analysis of the data identified a clear distinction between positive and negative perfectionism in samples from three different populations: athletes, individuals with eating disorders, and individuals with depression. Athletes were found to be high on positive perfectionism and low on negative perfectionism.

Individuals with eating disorders had high scores on both positive and negative perfectionism. Individuals with depression were high on negative perfectionism. It was concluded that negative perfectionism was a function of avoiding negative consequences, (e.g., avoiding failure, avoiding weight gain, avoiding the disapproval of others), and that positive perfectionism was a function of achieving positive consequences (e.g., goal achievement, approval of others).

Concern about the negative bias in the perfectionism literature lead another team of researchers to take up the issue of adaptive perfectionism. This led to the development of the Almost Perfect Scale (APS), which is the name of the subsequently developed scale and this particular approach to the conceptualization of perfectionism (Slaney, Rice, $\&$ Ashby, 2002). The intent was to approach the subject with an unbiased perspective and qualitative methodology to instruct the development of the theory (Slaney \& Ashby, 1996). The theory and subsequent research identified three aspects of perfectionism: (a) 
high standards, (b) order, and (c) discrepancy. Numerous investigations have been conducted and the evidence confirmed the existence of two higher order factors of perfectionism similar to the adaptive and maladaptive dimensions discussed above (Slaney, Rice, Mobley, Trippi, \& Ashby, 2001). The "high standards" and "order" dimensions correspond to adaptive characteristics and the "discrepancy" dimension corresponds to maladaptive characteristics. These findings have been replicated with college student populations (Johnson \& Slaney, 1996), diverse cultural groups (Mobley, Slaney, \& Rice, 2005), couples (Shea, Slaney, \& Rice, 2006), and children (Rice \& Preusser, 2002).

A review of the anecdotal and empirical literature provides support for both adaptive and maladaptive aspects of perfectionism (Stoeber \& Otto, 2006), but the issue still provokes some controversy in the field (Enns \& Cox, 2002). There is an ongoing debate between the dimensional approaches, particularly that of Hewitt and Flett (see Flett \& Hewitt, 2006) and the group (i.e., positive and negative) approaches (Slade \& Owens, 1998). Flett and Hewitt (2006) have questioned the existence of positive perfectionism and stated their belief that the term, "perfectionist," should be used only for individuals who rigidly hold to their standards even though the situation does not call for perfection, and who continue to set unreasonably high standard in several life domains. They used the term, "conscientiousness," to describe the construct of positive perfectionism that is supported in the empirical literature.

Some of the argument can be attributed to semantic disagreement, but the debate highlights the insidious nature of perfectionism: good intentions often identified as 
healthy, desirable, and the mark of success can take a pathological turn. The following two statements from the Hewitt and Flett MPS illustrate this paradox: "I set very high standards for myself" and "I strive to be the best at everything I do" (Hewitt \& Flett, 1991b). This kind of thinking is not necessarily pathological when standing alone (Frost et al., 1993). Perhaps the presence of perfectionistic thinking may not necessarily lead to maladaptive perfectionism. Instead, what matters is the way in which the individual interacts with their perfectionistic thoughts.

This idea is supported by findings that show the presence of both positive and negative perfectionism within an individual (i.e., a positive correlation between positive and negative perfectionism; Flett $\&$ Hewitt, 2006). The presence of adaptive perfectionistic thinking (e.g., "I set very high standards for myself') alongside maladaptive perfectionism suggests a rigid or inflexible interaction with what may otherwise be considered adaptive thoughts.

This idea of inflexibility is supported in a relatively new conceptual model that integrates both sides of the debate. From the dimensional approaches a distinction has emerged between perfectionistic strivings (e.g., striving for excellence) and perfectionistic concerns (e.g., worry about making a mistake), whereas the group approach divides positive and negative perfectionists. Using this distinction, a framework has been developed that integrates the dimensional and group approaches (Stoeber \& Otto, 2006). In this framework, perfectionists and nonperfectionists can be identified by the presence of any perfectionistic strivings. The differentiation between positive and negative perfectionists is made using the level of perfectionistic concerns. Perfectionistic 
concerns are characterized by rigid and inflexible concern over mistakes, doubts about actions, evaluation of the discrepancy between achievement and standards, self-criticism, and a fear of failure. Using this model, adaptive perfectionists would be high in perfectionistic strivings and low in perfectionistic concerns while maladaptive or pathological perfectionists would be high in perfectionistic strivings and concerns. These additional variables help to more accurately describe the construct and suggest that the focus of pathology should be on perfectionistic concerns. This approach provides some clarity to the debate by moving beyond the dichotomous argument and integrating the available evidence. This model also highlights some important implications for the current investigation in which it is hypothesized that the pathology associated with high standards is found in the inflexibility of the psychological interaction with those high standards.

Currently, there are several theoretical approaches to the construct of perfectionism. Taken together, it appears that perfectionism can involve both intrapersonal and interpersonal dimensions as well as both adaptive and maladaptive features. Despite the assertions of the proponents of the different theories, the overall evidence is in support of these ideas, and it is clear that research and applied work with perfectionism should take into account the subdimensions of perfectionism (i.e., maladaptive vs. adaptive) that impact the presentation of the phenomenon. It is also clear there may be additional variables of interest that might explain how positive or adaptive strivings can also lead to maladaptive outcomes. This is consistent with the hypothesis of this investigation that the level of rigidity or psychological inflexibility may mediate the 
level of pathology in the context of high standards. This logic has important implications for the current investigation into how perfectionism is manifest in religious/spiritual attitudes and behaviors.

\section{Perfectionism in Context}

A major area of inquiry in the perfectionism literature has been the study of the role of perfectionism in the context of environments characterized by high standards. This includes research in the domains of sports and exercise, education, professional achievement, and religion or spirituality. It is conceivable that the high standards environments could foster perfectionistic behaviors, or conversely, that perfectionistic behaviors could be reinforced in these environments.

The field of sports and exercise is characterized by high achievement and performance standards leading to questions about an association with perfectionism. Despite the focus on perfect performance in sports, maladaptive perfectionism has been found to undermine athletic performance and increase dissatisfaction with performance (Flett \& Hewitt, 2005). Maladaptive perfectionism in sports has been associated with low self-esteem (Gotwals, Dunn, \& Wayment, 2003) and deteriorating performance in response to negative feedback (Anshel \& Mansouri, 2005). Negative perfectionism has been linked to disturbed eating attitudes among female athletes, while no relationship emerged between positive perfectionism and disturbed eating attitudes (Haase, Prapavessis, \& Owens, 1999).

Perfectionism has been examined in the context of educational standards of achievement. Positive perfectionism has been associated with higher academic and 
interpersonal adjustment in middle school students, while negative perfectionists displayed greater emotional distress and lower interpersonal adjustment (Gilman \& Ashby, 2003). Maladaptive perfectionism has been linked to poor adjustment in college students (Rice \& Dellwo, 2002). Gifted students, a population noted for very high standards, have also been studied by perfectionism researchers. Amidst these high standards, it is still possible to distinguish between maladaptive and adaptive forms of perfectionism, and maladaptive perfectionism has been linked to low self-esteem and interpersonal difficulties (Parker, 2002). A survey of medical, dental, pharmacy, and nursing students found greater levels of psychological distress were associated with perfectionism and the imposter phenomenon (Henning et al., 1998), and maladaptive perfectionism was found to predict symptoms of depression and hopelessness in another longitudinal study of medical students (Enns, Cox, Sareen, \& Freeman, 2001).

Perfectionism and professional achievement have been linked in a handful of studies. Socially prescribed perfectionism has been connected to job stress and low job satisfaction in professional teachers (Flett, Hewitt, \& Hallett, 1995). A sample of career mothers displayed correlations between negative perfectionism and cynicism, exhaustion, parental distress, and overall life dissatisfaction (Mitchelson \& Burns, 1998). In a study of professional musicians, actors, and dancers; self-oriented and socially prescribed perfectionism were correlated with increased debilitating performance anxiety, somatic anxiety, and less goal satisfaction (Mor, Day, Flett, \& Hewitt, 1995).

High standards have generally been associated with religion and spirituality (Ashby \& Huffman, 1999), leading to a logical inquiry about the relationship between 
perfectionism and religion. There is a small body of research dedicated to examining this relationship with varied results. This relationship is only introduced here to highlight the presence of perfectionism in the context of high religious/spiritual standards. This will allow for a brief departure to address the theory and research on the subject of religiosity.

\section{Religiosity}

Consistent with the breadth of the subject, there are many different definitions for religion. This is true even when the search for a definition is limited to the psychological descriptions of the phenomenon. Generally, religion is characterized by a belief in a divine power or being and the subsequent association with a ritual based community. Spirituality has come to stand for the more personal or subjective dimension of the relationship with a higher power, whether or not that occurs in conjunction with the specified rituals and religious community (Wulff, 1996). In the past, religion and spirituality have been used synonymously in the study of religion, but there has been a movement to differentiate the terms (Zinnbauer \& Pargament, 2005). Currently, most individuals who identify themselves as "religious" also identify themselves as "spiritual" while a smaller group identifies themselves as "spiritual" but not "religious" (Hood \& Belzen, 2005). Religiosity is a term from sociology used to describe the multiple dimensions that fall under the umbrella of religion or spirituality including religious beliefs, practices, attitudes, orientation, development, commitment, involvement, experiences, and values as well as the more subjective dimensions of spirituality, mysticism, and attributional style (Hill \& Hood, 1999). 
Several important figures in the history of psychological thought have addressed the issue of religion and spirituality in the human experience. Broadly speaking, their thinking falls within two approaches to the subject: (a) the descriptive approach marked by attempts to document the varieties and different types of religious experience, and (b) the explanatory approach marked by attempts to find the origin of the phenomenon within the realm of psychological, biological, and environmental explanations. These two approaches also became associated with positive and negative views on the subject with the descriptive theorists being in support of religion and the explanatory theorists being somewhat critical of the subject (Wulff, 1996). This dichotomous approach is encapsulated in the humanistic views on religion where it was argued that the nature of the religious experience, whether good or bad, was dependent on the individual's response to the experience.

Some early theorists took the position that religion could be an asset to healthy psychological and overall functioning. James (1985) referred to religion as an essential part of life and attributed human excellence to a combination of intellect and spiritual inspiration. Jung's (1938) description of healthy religion is similar to the contemporary view of spirituality described above, and he regarded the acquisition or reacquisition of a religious outlook on life as integral to complete recovery from psychological problems. While skeptical of the dogma and practices that typically defined religion, Jung saw a place for them in helping an individual maintain the religious outlook they had gained from personal experience. Erikson (1966) regarded religion as an important resource in his developmental stages and a necessary ingredient for human maturity. Erikson 
believed that religion fosters trust and hope, two key elements of the infantile stage of development, and religion provides support for the attainment of wisdom, the final stage of human development.

Religion has also been regarded as harmful to psychological well-being. Skinner (1953) described religion as one more system of external control, explaining all religious behavior as the result of complex contingencies of reinforcement. He was critical of the use of punishment that historically had been exploitative of the individual to benefit the power of religious authorities. Freud (1961) referred to religion as an obsessional neurosis and cited the susceptibility to guilt, the compulsive nature of religious rituals, and behaviors motivated by fear as evidence of pathology. Contrary to science and reason, religion is an illusion according to Freud in which the individual is discouraged from critical analysis of the phenomenon and rigidly represses any instinctual thoughts and impulses.

Allport has been one of the more influential figures in the psychology of religion (Donahue, 1985; Hunt \& King, 1971). His concept of religious orientation drew attention to the individual's role in the pathological nature of religion. Responding to a distressing relationship between religiosity and prejudicial attitudes, he developed a theory and accompanying scale for measuring intrinsic and extrinsic religious orientation to shed some light on religion and prejudice (Allport \& Ross, 1967). Individuals with an intrinsic orientation are characterized by the internalization of their religious beliefs, which serve as their primary motivation. Individuals with an extrinsic orientation are characterized by their use of religion for selfish and utilitarian ends such as security, solace, socialization, 
distraction, or status. Individuals who displayed both intrinsic and extrinsic qualities were described as indiscriminately proreligious, and individuals who displayed neither intrinsic nor extrinsic qualities were described as indiscriminately antireligious or nonreligious.

The literature at the time suggested that religious individuals with an extrinsic orientation would adopt the authoritarian and ethnocentric attitudes often associated with dogmatic religious traditions while religious individuals with an intrinsic orientation would reject these negative attitudes and behaviors. This was confirmed in the investigation by Allport and Ross (1967) with some additional findings. They found that indiscriminately pro-religious individuals (i.e., both intrinsic and extrinsic orientations) were characterized by a consistent response style which was attributed to an "undifferentiated cognitive disposition" (e.g., the religion as a whole is good while a minority group as a whole is bad, pp. 441-442), and that these individuals were the most prejudiced of all. This was attributed to the tendency to overgeneralize and stereotype indicating that they were relatively inflexible in their response to religious teachings, practices, and the need to make fine distinctions in a complex environment. Thus, a portion of the pathological nature of religion was attributable to individual differences and a rigid response to the religion.

The intrinsic-extrinsic (I-E) framework developed by Allport (Allport \& Ross, 1967) has been the dominant conceptual and measurement paradigm in the study of the psychology of religion (Kirkpatrick \& Hood, 1990). While the scale purports to measures religious orientation or motivation, it has been widely used as a general indicator of overall religiosity or religiousness. 
Similar to the perfectionism literature, the intrinsic-extrinsic framework highlights the importance of identifying subdimensions of the construct to fully understand the presentation of religiosity. In this case, extrinsic religiosity, the more maladaptive form of religiosity, was responsible for the association between religiosity and negative prejudicial attitudes.

\section{Perfectionism and Religiosity}

Making a connection between perfectionism and religiosity seems logical given the features of both constructs. As demonstrated above, there is a line of inquiry investigating the nature of perfectionism in the context of high standards. One of the hallmarks of religion has been high standards and expectations. The literature connecting religiosity and mental health has identified the unreasonable pursuit of perfection as a possible causal factor in the shame, guilt, and depression associated with religiosity. Indeed, Christian religions are characterized by an expectation of perfection, which suggests that perfectionism and religiosity may be linked (Timpe, 1989). Scriptural commandments such as those found in the Sermon on the Mount in the New Testament set high standards of behavior and explicit commandments to "Be ye therefore perfect" (Matthew 5:48). These directions for perfection are interpreted as a gradual and cumulative process, but it is acknowledged that these expectations can take a pathological turn for some individuals leading to frustration and depression (Nelson, 1995).

Perfectionism has been examined in the context of religion from many angles, although much of it is theoretical or anecdotal. For example, it has been thought to be a 
pathological version of positive striving (Heise \& Steitz, 1991; MacKenna, 2007; Timpe, 1989). Depression among religious populations has been attributed to distorted understandings of biblical expectations of perfection (McCandless, 1991). Moreover, it is often linked to underlying emotions of guilt and shame in religious populations (Sorotzkin, 1998).

Some of the empirical research on the association between perfectionism and religiosity is couched in studies investigating the relationship between OCD and religiosity. Catholic, Jewish, and Protestant populations have all been evaluated for features of obsessive-compulsive disorder. This literature is relevant here because perfectionism is considered to be one of the domains of OCD, but has to be viewed with caution because the measurement of perfectionism in this research often does not account for the subdimensions (i.e., adaptive and maladaptive) of perfectionism (Frost \& DiBartolo, 2002). In a study of 54 Italian Catholics, individuals with a high degree of religiosity scored higher than individuals with a lower degree of religiosity on a measure of perfectionism contained within a questionnaire to assess for OCD, and it was concluded that religiosity may play a role in obsessive-compulsive features (Sica, Novara, \& Sanavio, 2002). In a similar study with Israeli Jews, religiosity was marginally correlated with self-oriented perfectionism $(r=.12, p<.05$; Zohar, Goldman, Calamary, \& Mashiah, 2005). A study of protestant religiosity and OCD revealed no significant association or between group differences between religiosity and perfectionism when measured as a sub domain of OCD on the Obsessional Beliefs Questionnaire (Abramowitz, Deacon, Woods, \& Tolin, 2004), but these findings should be interpreted 
with caution as the measure of perfectionism did not account for the subdimensions of the construct. Overall the OCD and religiosity literature are suggestive of a relationship, and the research highlights the importance of identifying the subdimensions of perfectionism to truly understand the relationship.

Two studies have examined the specific relationship between perfectionism and religiosity, and help clarify the nature of the relationship by taking the subdimensions of the constructs into account. Citing the high standards and expectations as the common denominator between the two constructs, perfectionism was compared to religiosity in 242 undergraduate college students (Ashby \& Huffman, 1999). The revised edition of the APS was used to measure both adaptive and maladaptive dimensions of perfectionism and religiosity was measured by asking about the level of religious activity and an intrinsic-extrinsic religiosity measure. Increased religious activity and intrinsic religiosity were positively associated with the adaptive dimensions of perfectionism (i.e., high standards and order). Maladaptive perfectionism was not related to religiosity, intrinsic or extrinsic, but a similar study found complementary results. In a survey of 500 Christian college students, a significant positive correlation was found between maladaptive perfectionism and problematic spiritual functioning (e.g., instability and disappointment with one's relationship with God; Thelander, 2002). Significant small negative correlations were also found between maladaptive perfectionism and mature aspects of spiritual functioning (e.g., awareness of God and acceptance of spiritual disappointments). Taken together, these two studies suggest that adaptive perfectionism can associated with adaptive religiosity and maladaptive perfectionism can be associated 
with maladaptive religiosity.

The connection between perfectionism and religiosity seems likely because of their shared high standards. When the constructs are compared using adaptive and maladaptive subdimensions, the relationship is clarified further. It appears, then, that the relationship between perfectionism and religiosity can best be described by accounting for the subdimensions of the construct. Specifically, it appears that the adaptive and maladaptive distinction in both religiosity and perfectionism helps explain how religious standards in well-meaning individuals can be associated with negative outcomes (i.e., maladaptive perfectionism). This leads to the primary research question at hand in this investigation which looks at why this established relationship exists using a mediational variable (Baron \& Kenny, 1986).

\section{Psychological Inflexibility}

The idea of a mediational variable that could explain why this relationship exists emerged from the review of the literature in which psychological inflexibility and rigidity was regularly implicated in the literature examining both perfectionism and religiosity. For example, Freud (1959) blamed an intolerant superego for perfectionism, and he criticized religion for leading people to rigidly repress natural instincts and impulses (1961). Beck's (1976) idea of polarized or all-or-nothing thinking is characterized by rigidity and inflexibility. Inflexible high standards were a key part of one definition of perfectionism (Hamachek, 1978). The Hewitt and Flett (1991b) multidimensional perfectionism theory portrayed perfectionistic standards as exacting, and they described 
perfectionists as rigidly holding to standards (Hewitt \& Flett, 2002). Perfectionistic concerns were typified by rigid and inflexible concern over mistakes (Stoeber \& Otto, 2006). Perfectionism as a feature in obsessive-compulsive personality disorder is characterized by rigidity (American Psychological Association, 2000). People described as indiscriminately proreligious were depicted as inflexible in their response to religious teachings (Allport \& Ross, 1967).

In all of these examples from the literature, maladaptive perfectionism and religiosity are attributed to psychological rigidity and inflexibility. The relationship between maladaptive perfectionism and maladaptive religiosity can lead to obvious questions about causation. For example, does maladaptive perfectionism lead to maladaptive religiosity? However, the implication of an underlying psychological inflexibility, suggested that this relationship might best be explained using psychological inflexibility as a mediator.

Psychological inflexibility as a construct is a component of the model of psychopathology described by ACT (Hayes et al., 1999, 2006). Generally defined, it refers to a rigid and inflexible style of responding to unwanted private experiences (e.g., thoughts, feelings, bodily sensations). When faced with an aversive experience, a psychologically inflexible individual will have a narrow range of response options instead of a wide range of possibilities (Wilson \& Murrell, 2004).

The ACT model is comprised of six psychological processes that together define the construct of psychological inflexibility (Hayes et al., 2006). These processes are:

1. Experiential avoidance, which is characterized by excessive negative 
evaluations of unwanted internal events (i.e., thoughts, feelings, and bodily sensations) and an unwillingness to experience these events. This reluctance is followed by attempts to control or avoid these unwanted experiences, which is often beneficial in the shortterm, but results in negative long-term consequences.

2. Cognitive fusion, which is characterized by attempts to change the form or frequency of thoughts because they are believed and taken literally.

3. Self as content, which is characterized as an attachment to a conceptualization of the self that is based on the content of the individual's private experiences (e.g., "I feel bad so I must be a bad person").

4. Not being present, which is characterized by the dominance of a negatively conceptualized past and the fear of the future rather than living in the present moment.

5. Lack of values, which is characterized by the lack of clear values or direction in the life of the individual

6. Inaction, which is characterized by the lack of action that is consistent with an individual's chosen and valued directions. These six processes are the target of ACT and are countered by the positive psychological processes of acceptance, defusion, self as context, being present, values clarity, and committed action.

Movement of the six processes targeted by ACT, including a decrease in negative processes and an increase in positive processes, is measured by the Acceptance and Action Questionnaire (AAQ; Hayes, Strosahl et al., 2004). This scale is comprised of 22 items that were selected from a pool of items created by ACT therapists. There are two validated versions of the scale. The 16-item version loads on two factors: acceptance/ 
mindfulness and values-based action, both of which load on a higher order factor that is referred to a psychological flexibility. There is also a 9-item version that loads on a single factor of psychological flexibility (Hayes et al., 2006).

There is a body of both correlational and experimental treatment research with ACT. The correlational research using the AAQ is relevant here because it supports the use of the measure as a predictive variable and identifies the influence of psychological inflexibility in a number of pathological conditions. Psychological inflexibility as measured by the AAQ has been found to be associated with general health, depression, negative affect, anxiety, social phobia, posttraumatic stress disorder, self-harm, and alcohol dependence (Hayes et al., 2006; Hayes, Masuda, Bissett, Luoma, \& Guerrero, 2004).

Psychological inflexibility identifies the nature of the individual's interaction with their environment and private experiences. The construct provides a possible explanation for why some individuals develop pathological conditions where others may not in the same circumstances. For example, inflexibility has been proposed as the mechanism by which some individuals develop anxiety disorders in the context of normative fears (e.g. traumatic incidents) while others do not (Olatunji et al., 2007).

\section{Conclusion}

A review of the perfectionism and religiosity literature confirmed the logic of examining the relationship between perfectionism and religiosity because of their shared high standards. Research in both areas has also identified the importance of accounting 
for adaptive and maladaptive dimensions of the constructs. This is especially important when examining relationships between the two constructs and with other variables as a failure to do so can lead to inconclusive results.

When the adaptive and maladaptive dimensions are accounted for, it appears that adaptive perfectionism is related to adaptive religiosity and maladaptive perfectionism is related to maladaptive religiosity. The idea of a mediational variable that could explain why this relationship exists emerged from the review of the literature in which a rigid and inflexible personality style was regularly implicated in the literature examining both perfectionism and religiosity. The idea that psychological inflexibility could explain this relationship was supported by the literature and research questions were developed accordingly

\section{Research Questions and Hypotheses}

To examine the relationship between perfectionism and religiosity and how this relationship is mediated by psychological inflexibility, a set of research questions and hypotheses were constructed to guide the data collection and analyses. Because of the importance of accounting for adaptive and maladaptive dimensions of the constructs, scales that measured subdimensions of the constructs of perfectionism and religiosity were identified to capture these individual differences.

To measure the construct of perfectionism, the Almost Perfect Scale-Revised (APS-R; Slaney et al., 2001) fit the multidimensional criteria as it measured both adaptive (high standards and order) and maladaptive (discrepancy) dimensions of 
perfectionism. It was clear from the perfectionism literature that it was important to address both positive and negative aspects of perfectionism. This was also apparent in the religiosity literature, as the type of perfectionism (positive or negative) influenced the relationship between perfectionism and religiosity (Ashby \& Huffman, 1999).

To measure the construct of religiosity, a scale that measured the two types of religious orientation, internal and external, as originally proposed by Allport and Ross (1967), seemed most appropriate. This theory fit the multidimensional criteria of this investigation, and it was from the original investigation that the idea of psychological rigidity emerged as a possible mediating variable.

This idea of psychological inflexibility was implicated throughout the literature, so a measure was identified that would provide a clear measure of this construct. The AAQ was developed to measure the ACT processes provided a good measure of this construct and was recently revised resulting in a single factor scale to measure psychological inflexibility (Bond et al., 2009).

\section{Research Question 1}

What is the correlation between an internal religious orientation, as measured by the Age Universal Religious Orientation Scale (Gorsuch \& Venable, 1983), and the three dimensions of perfectionism (high standards, order, and discrepancy), as measured by the APS-R (Slaney et al., 2001)?

Hypothesis A. An internal religious orientation will be positively correlated with the high standards dimension of perfectionism.

Hypothesis B. An internal religious orientation will be positively correlated with 
the order dimension of perfectionism.

Hypothesis $C$. An internal religious orientation will be negatively correlated with the discrepancy dimension of perfectionism.

\section{Research Question 2}

What is the correlation between an external religious orientation, as measured by the Age Universal Religious Orientation Scale (Gorsuch \& Venable, 1983), and the three dimensions of perfectionism (high standards, order, and discrepancy), as measured by the APS-R (Slaney et al., 2001)?

Hypothesis A. An external religious orientation will be positively correlated with the high standards dimension of perfectionism.

Hypothesis B. An external religious orientation will be positively correlated with the order dimension of perfectionism.

Hypothesis C. An external religious orientation will be positively correlated with the discrepancy dimension of perfectionism.

\section{Research Question 3}

What is the correlation between psychological inflexibility, as measured by the Acceptance and Action Questionnaire-II (Bond et al., 2009), and the two dimensions of religious orientation, as measured by the Age Universal Religious Orientation Scale (Gorsuch \& Venable, 1983)?

Hypothesis A. Psychological inflexibility will not be correlated with an internal religious orientation. 
Hypothesis B. Psychological inflexibility will be positively correlated with an external religious orientation.

\section{Research Question 4}

What is the correlation between psychological inflexibility, as measured by the Acceptance and Action Questionnaire-II (Bond et al., 2009), and the three dimensions of perfectionism (high standards, order, and discrepancy), as measured by the APS-R (Slaney et al., 2001)?

Hypothesis A. Psychological inflexibility will not be correlated with the high standards dimension of perfectionism.

Hypothesis B. Psychological inflexibility will not be correlated with the order dimension of perfectionism.

Hypothesis C. Psychological inflexibility will be positively correlated with the discrepancy dimension of perfectionism.

\section{Research Question 5}

Does psychological inflexibility, as measured by the Acceptance and Action Questionnaire-II (Bond et al., 2009), mediate the relationship between an internal religious orientation, as measured by the Age Universal Religious Orientation Scale (Gorsuch \& Venable, 1983), and the three dimensions of perfectionism (high standards, order, and discrepancy), as measured by the APS-R (Slaney et al., 2001)?

Hypothesis A. Psychological inflexibility will not mediate the relationship between an internal religious orientation and the high standards dimension of 
perfectionism.

Hypothesis B. Psychological inflexibility will not mediate the relationship between an internal religious orientation and the order dimension of perfectionism.

Hypothesis C. Psychological inflexibility will not mediate the relationship between an internal religious orientation and the discrepancy dimension of perfectionism.

\section{Research Question 6}

Does psychological inflexibility, as measured by the Acceptance and Action Questionnaire-II (Bond et al., 2009), mediate the relationship between an external religious orientation, as measured by the Age Universal Religious Orientation Scale (Gorsuch \& Venable, 1983), and the three dimensions of perfectionism (high standards, order, and discrepancy), as measured by the APS-R (Slaney et al., 2001)?

Hypothesis A. Psychological inflexibility will not mediate the relationship between an external religious orientation and the high standards dimension of perfectionism.

Hypothesis B. Psychological inflexibility will not mediate the relationship between an external religious orientation and the order dimension of perfectionism.

Hypothesis C. Psychological inflexibility will mediate the relationship between an external religious orientation and the discrepancy dimension of perfectionism. 
CHAPTER III

METHOD

\section{Design}

A correlational design was used to study the relationship between perfectionism and religiosity as mediated by psychological inflexibility.

\section{Procedures}

Participants were recruited from undergraduate general/introductory psychology classes and with fliers placed throughout the campus. The recruitment information provided a link to an online survey. The online survey included an informed consent page, and participants who agreed to participate were directed to the online survey containing the questionnaires. The online survey was hosted by a third party provider of electronic survey services. The survey took approximately 30 minutes to complete, and participants were allowed to discontinue at any time. The participant responses to the survey questions were anonymous and are not connected to any identifying information. Because several individual measures were administered, the measures were administered in random order for each participant to counterbalance for the effects of the order of administration.

\section{Participants}

Undergraduate college students from Utah State University attending in the fall 
2008 semester were asked to participate (see Appendix B). Only individuals over the age of 18 were allowed to participate (see Appendix C). In total, 421 individuals accessed the online survey, but 45 participants did not complete all of the questions. Inspection of the data did not reveal any systematic reasons for the incomplete data, and it was assumed that the incomplete cases were randomly distributed throughout the data set. These cases were removed from the data set resulting in 376 total participants that were included in the analyses, of which $231(61.4 \%)$ were female and $145(38.6 \%)$ were male. The average age of the participants was 19.59 years $(S D=4.75)$ and the average number of years of post high school education was $1.34(S D=4.75)$. The majority of the participants were single $(92.0 \%)$ and Caucasian $(92.8 \%)$. The majority the participants endorsed "Latter-day Saint" (84.3\%) for current religious affiliation followed by "No Affiliation" (9.6\%). The complete demographic characteristics of the sample are listed in Table 1.

\section{Measures}

The survey included questions about demographics, perfectionism, religiosity, and psychological inflexibility (see Appendix A).

\section{Demographics}

The demographics questionnaire included questions about sex, age, marital status, education, ethnicity/race, current religious affiliation, any past religious affiliation, the importance of religion, and religious activity. 
Table 1

Demographic Characteristics

\begin{tabular}{lcc}
\hline Variable & $\%$ or $M$ & $S D$ \\
\hline Sex & & \\
$\quad$ Male & $38.6 \%$ & \\
$\quad$ Female & $61.4 \%$ & 4.75 \\
Age & 19.59 & \\
Marital status & & \\
$\quad$ Single & $92.0 \%$ & \\
$\quad$ Married & $7.2 \%$ \\
Divorced & $0.3 \%$ \\
$\quad$ Separated & $0.3 \%$ \\
$\quad$ Remarried & $0.3 \%$ \\
Education & \\
$\quad$ Post high school (years) & 1.34 \\
Race/ethnicity & \\
African American & $1.1 \%$ \\
Asian American & $0.8 \%$ \\
$\quad$ Caucasian & $92.8 \%$ \\
Hispanic & $2.9 \%$ \\
Native American & $0.8 \%$ \\
Other & $1.6 \%$ \\
Religion & \\
Baptist & $1.1 \%$ \\
Catholic & $3.2 \%$ \\
Latter-day Saint & $0.3 \%$ \\
Lutheran & $0.3 \%$ \\
Methodist & $0.5 \%$ \\
No affiliation & \\
Other &
\end{tabular}

\section{Perfectionism}

Information about perfectionism was obtained using the APS-R (Slaney et al., 2001). The APS-R takes into account the body of research that has identified both positive and negative dimensions of perfectionism and provides specific measures of the 
defining features of perfectionism (high standards and extreme self-criticism). It is made up of 23 items that are responded to on a Likert scale with 7 scale points ranging from "strongly disagree" to "strongly agree" (Mobley et al., 2005). The APS-R contains three subscales: (a) high standards (7 items), (b) discrepancy (12 items), and (c) order (four items). The high standards and order subscales are associated with the aspects of positive perfectionism and the discrepancy subscale is associated with the aspects of negative perfectionism. The subscales can be used to distinguish between adaptive and maladaptive perfectionists with adaptive perfectionists scoring high on high standards and low on discrepancy and maladaptive perfectionists scoring high on both high standards and discrepancy (Ashby \& Kottman, 1996). Internal consistency of the APS-R has ranged from .85 to .92 . Additionally, the APS-R has been shown to correlate with the expected outcomes of perfectionism including depression, self-esteem, and GPA (Slaney et al., 2002). Cronbach's alpha for the current sample was .87 for high standards, .88 for order, and .94 for discrepancy.

The APS-R was chosen because it covers both adaptive and maladaptive dimensions of perfectionism in a clear manner. The APS-R also has a rigorous body of psychometric support and has been widely used with the population of interest in this investigation.

\section{Religiosity}

Information about religiosity was gathered using the Age Universal Religious Orientation Scale (AUROS; Gorsuch \& Venable, 1983). This 20-item measure contains two subscales designed to measure intrinsic and extrinsic (I-E) religious orientation. It is 
a modified version of the I-E Religious Orientation Scale (Allport \& Ross, 1967) updated for use with children and adults. The AUROS is completely interchangeable with the original scale. Nineteen of the 20 items are scored on a 5-point Likert scale with 1 indicating "strong disagreement" and 5 indicating "strong agreement." The other item is a measure of church attendance where 1 indicates "a few times a year" and 5 indicates "more than once a week." Internal consistency ranged from .66 to .73. Cronbach's alpha for the current sample was .93 for intrinsic religiosity and .69 for extrinsic religiosity.

The AUROS was chosen as a measure of religiosity because it provides both a general indication of religiosity and differentiates between two types of religiosity: intrinsic religiosity characterized by the internalization of religious beliefs that serve as primary motivation; and extrinsic religiosity characterized by the use of religion for selfish and utilitarian ends such as security, solace, socialization, distraction, or status. It was hoped that these subtypes of religiosity would provide further understanding of the individual difference apparent in the literature examining the relationship between perfectionism and religiosity. The age universal version was chosen because it used language that was accessible and clear for a diverse group of religious affiliations.

\section{Psychological Inflexibility}

Information about psychological inflexibility was gathered using the Acceptance and Action Questionnaire-II (AAQ-II; Bond et al., 2009). The AAQ-II is a revised version of the original Acceptance and Action Questionnaire designed to measure the unidimensional construct of psychological flexibility. The ACT theory focuses on positive attributes so higher scores indicate higher flexibility. In this study, the variable of 
interest is the inflexibility of the participants, so lower scores will indicate greater inflexibility. The scale is comprised of 10 items that yield a single factor solution (psychological flexibility). Normative research with over 3,000 participants resulted in internal consistency ranging from .76 to .87 and test-retest reliability ranging from .78 to .80. The AAQ-II has also demonstrated concurrent validity with theoretically similar scales as demonstrated by negative associations with depression, anxiety, stress, and overall psychological distress. Cronbach's alpha for the current sample was .85 .

The AAQ-II was chosen because it has proven to be a good measure of overall psychological inflexibility. This construct was implicated in the perfectionism and religiosity literature, but as a byproduct of other analyses and it was never directly measured. The AAQ-II is unique as it provides a direct measure of psychological inflexibility. 


\section{CHAPTER IV}

\section{RESULTS}

Table 2 is a summary of the descriptive statistics for the measures used in this investigation. It provides the count of scores, range of scores, minimum score, maximum score, mean score, and standard deviation for the measures of perfectionism, religious orientation, and psychological inflexibility. Visual inspection of the score distributions indicated that each measure approximated the normal distribution. Skewness statistics are reported in Table 2.

\section{Perfectionism and Religiosity}

\section{Research Question 1: Perfectionism and Internal Religious Orientation}

To address research question 1, the correlation between an internal religious orientation, as measured by the AUROS (Gorsuch \& Venable, 1983), and the three

Table 2

Descriptive Statistics for Measures of Perfectionism, Religious Orientation, and Psychological Inflexibility

\begin{tabular}{lcccccr}
\hline Scale/subscale & Min & Max & Range & $M$ & $S D$ & Skew \\
\hline High standards perfectionism & 7 & 49 & 42 & 41.09 & 5.59 & -1.33 \\
Order perfectionism & 4 & 28 & 24 & 21.16 & 4.16 & -.86 \\
Discrepancy perfectionism & 12 & 83 & 71 & 40.90 & 14.82 & .46 \\
Internal religious orientation & 9 & 44 & 35 & 33.94 & 8.65 & -1.59 \\
External religious orientation & 11 & 55 & 44 & 27.75 & 5.95 & -.02 \\
Psychological inflexibility & 22 & 70 & 48 & 50.73 & 8.84 & -.68 \\
\hline
\end{tabular}


dimensions of perfectionism (high standards, order, and discrepancy), as measured by the APS-R (Slaney et al., 2001). Hypotheses were proposed for each of these dimensions.

It was hypothesized that an internal religious orientation would be positively correlated with the high standards dimension of perfectionism. This hypothesis was supported. As shown in Table 3, there is a small positive correlation between these two variables $(r=.26, p<.01$, two-tailed).

It was hypothesized that an internal religious orientation would be positively correlated with the order dimension of perfectionism. This hypothesis was not supported. As shown in Table 3, there was not a significant relationship between these two variables.

It was hypothesized that an internal religious orientation would be negatively correlated with the discrepancy dimension of perfectionism. This hypothesis was not supported. As shown in Table 3, there was not a significant relationship between these two variables.

\section{Research Question 2: Perfectionism and External Religious Orientation}

Research question 2 examined the correlation between an external religious

\section{Table 3}

Correlations Between Perfectionism Dimensions and Religious Orientation

\begin{tabular}{lccc}
\hline & \multicolumn{3}{c}{ Perfectionism } \\
\cline { 2 - 4 } Subscale & High standards & Order & Discrepancy \\
\hline Internal religious orientation & $.26^{* *}$ & .10 & -.10 \\
External religious orientation & -.01 & -.05 & $.13^{*}$ \\
\hline$* \quad p<.05$, two-tailed. & & & \\
$* * p<.01$, two-tailed. & & &
\end{tabular}


orientation, as measured by the AUROS (Gorsuch \& Venable, 1983), and the three dimensions of perfectionism (high standards, order, and discrepancy), as measured by the APS-R (Slaney et al., 2001). Hypotheses were proposed for each of these dimensions.

It was hypothesized that an external religious orientation would be positively correlated with the high standards dimension of perfectionism. This hypothesis was not supported. As shown in Table 3, there was not a significant relationship between these two variables.

It was also hypothesized that an external religious orientation will be positively correlated with the order dimension of perfectionism. This hypothesis was not supported. As shown in Table 3, there was not a significant relationship between these two variables.

Finally, it was hypothesized that an external religious orientation would be positively correlated with the discrepancy dimension of perfectionism. This hypothesis was supported. As shown in Table 3, there is a small positive correlation between these two variables $(r=.13, p<.05$, two-tailed).

\section{Psychological Inflexibility}

It is also of interest how psychological inflexibility might be related to the variables of perfectionism and religiosity. Psychological inflexibility was measured by the AAQ-II, and lower scores reflect higher inflexibility. As such, a negative correlation would indicate a positive association between the two variables. 


\section{Research Question 3: Psychological Inflexibility and Religious Orientation}

Research question 3 examined the relationship between psychological inflexibility, as measured by the AAQ-II (Bond et al., 2009), and the two dimensions of religious orientation, as measured by the AUROS (Gorsuch \& Venable, 1983). As hypothesized, psychological inflexibility was not significantly related to internal religious orientation, but there was a significant negative correlation between psychological inflexibility and external religious orientation $(r=-.20, p<.01$, two-tailed $)$. This means that as individuals have higher levels of psychological inflexibility, it is likely they will score higher in external religious orientation.

\section{Research Question 4: Psychological Inflexibility and Perfectionism}

Research question 4 examined the relationship between psychological inflexibility, as measured by the AAQ-II (Bond et al., 2009), and the three dimensions of perfectionism (high standards, order, and discrepancy), as measured by the APS-R (Slaney et al., 2001). As hypothesized, psychological inflexibility is not significantly related to the two positive dimensions of perfectionism (high standards and order), but psychological inflexibility is negatively correlated with the negative dimension of perfectionism, discrepancy $(r=-.54, p<.01$, two-tailed). This means that as individuals have higher levels of psychological inflexibility, it is likely they will have higher concerns about the discrepancy between their standards and performance. 


\section{Mediation}

A variable is said to function as a mediator if it can account for the relationship between an independent variable and a dependent variable (Baron \& Kenny, 1986). To some extent, a mediator can help explain how or why a relationship between two variables exists. The test for mediation as proposed by Baron and Kenny included three steps in which four conditions must be met. The three steps of a test of mediation are: (a) regress the mediator on the independent variable, (b) regress the dependent variable on the independent variable, and (c) regress the dependent variable on both the independent and dependent variables. This is not a stepwise or hierarchical process, and each regression analysis is performed separately.

Using the three regression analyses, a test of mediation is performed by evaluating four conditions. First, the independent variable must have a significant effect on the mediator in the first regression equation. Second, the independent variable must have a significant effect on the dependent variable in the second regression equation. Third, the mediator must have a significant effect on the dependent variable in the third regression equation. Finally, the effect of the independent variable on the dependent variable must be less in the third regression equation than in the second. If the first step is insignificant, further analyses are unnecessary. The need for performing the mediational analyses can be determined by examining the correlational results to determine if the first step would yield a significant result. For example, if the independent variable is not significantly correlated with the mediator, then further regression analyses are unnecessary. This logic can be applied to the additional steps of the test of mediation. 


\section{Research Question 5: Internal Religious \\ Orientation and Perfectionism Mediated by Psychological Inflexibility}

It was asked if psychological inflexibility, as measured by the AAQ-II (Bond et al., 2009), mediated the relationship between an internal religious orientation, as measured by the AUROS (Gorsuch \& Venable, 1983), and the three dimensions of perfectionism (high standards, order, and discrepancy), as measured by the APS-R (Slaney et al., 2001).

Because psychological inflexibility is typically associated with maladaptive outcomes, it was hypothesized that psychological inflexibility would not mediate the relationship between an internal religious orientation and any of the dimensions of perfectionism because internal religiosity is considered to be the more adaptive form of religiosity. The results of the analysis were consistent with this hypothesis as internal religiosity was not significantly correlated with psychological inflexibility rendering step one of the test of mediation insignificant for all three dimensions of perfectionism.

\section{Research Question 6: External Religious Orientation and Perfectionism Mediated By Psychological Inflexibility}

It was asked if psychological inflexibility, as measured by the AAQ-II (Bond et al., 2009), mediated the relationship between an external religious orientation, as measured by the AUROS (Gorsuch \& Venable, 1983), and the three dimensions of perfectionism (high standards, order, and discrepancy), as measured by the APS-R (Slaney et al., 2001).

It was hypothesized that psychological inflexibility would not mediate the 
relationship between an external religious orientation and the adaptive high standards or order dimensions of perfectionism. An examination of the correlational analyses showed no significant correlation between external religiosity and high standards or order perfectionism. While step one of the test of mediation would be significant (external religiosity is significantly correlated with psychological inflexibility), this lack of a relationship between external religiosity and high standards and order perfectionism would render step two of the test of mediation insignificant.

It was hypothesized that psychological inflexibility would mediate the relationship between an external religious orientation and the discrepancy dimension of perfectionism (see Figure 1).

As shown in Table 4, this hypothesis was supported. The correlational results indicated the need for a full test of mediation in which all four of the criteria for mediation were satisfied. In step one, a significant effect was found between the independent variable, external religious orientation, and the mediator, psychological

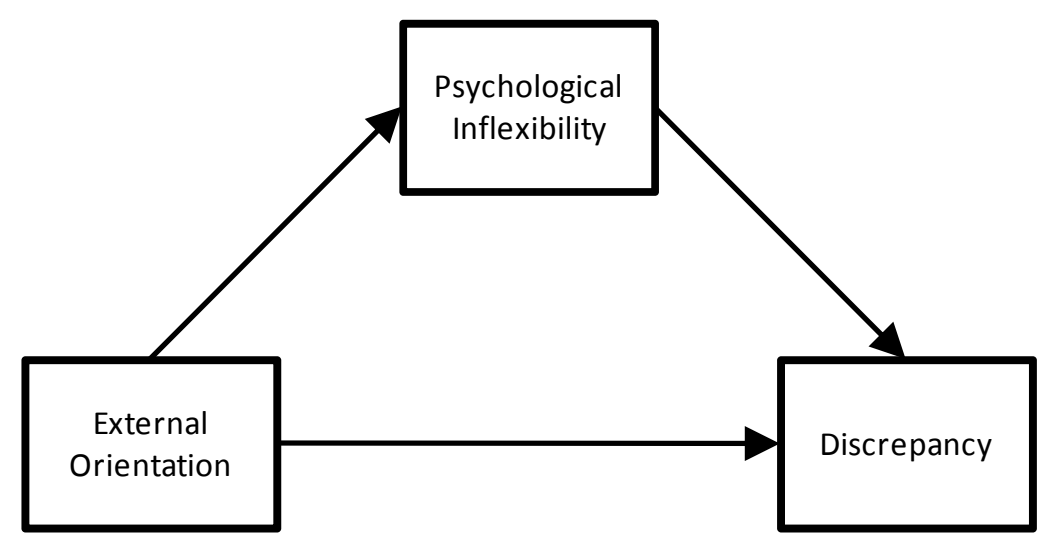

Figure 1. Psychological inflexibility as a mediator between external religiosity and discrepancy perfectionism. 
Table 4

Test for Mediation: Psychological Inflexibility as a Mediator Between External Religious Orientation and Discrepancy Perfectionism

\begin{tabular}{|c|c|c|c|c|c|c|c|}
\hline Step & $Y$ & $X$ & $\begin{array}{c}\text { B } \\
\text { (Std. Error) }\end{array}$ & $\begin{array}{l}\beta \\
(t)\end{array}$ & $R^{2}$ & $F$ & $\begin{array}{l}\text { Criteria for } \\
\text { mediation }\end{array}$ \\
\hline 1 & PI & ERO & $\begin{array}{l}-30 \\
(.08)\end{array}$ & $\begin{array}{l}-.20 \\
(4.01)^{* *}\end{array}$ & .04 & $16.09 * *$ & $\mathrm{Y}$ \\
\hline 2 & $\mathrm{D}$ & ERO & $\begin{array}{l}.31 \\
(.13)\end{array}$ & $\begin{array}{c}.13 \\
(2.43)^{*}\end{array}$ & .02 & $5.90^{*}$ & Y \\
\hline \multirow[t]{2}{*}{3} & $\mathrm{D}$ & ERO & $\begin{array}{l}.04 \\
(.11)\end{array}$ & $\begin{array}{l}.02 \\
(.34)\end{array}$ & .29 & $77.79 * *$ & $\mathrm{Y}$ \\
\hline & & PI & $\begin{array}{l}-.90 \\
(.07)\end{array}$ & $\begin{array}{c}-.54 \\
-12.14 * *\end{array}$ & & & $\mathrm{Y}$ \\
\hline
\end{tabular}

Note. $\mathrm{PI}=$ Psychological inflexibility, $\mathrm{ERO}=$ External religious orientation, $\mathrm{D}=$ Discrepancy perfectionism.

$* p<.05$.

$* * p<.001$.

inflexibility. As already seen in the correlational analyses, higher levels of external religious orientation predict higher levels of psychological inflexibility. In step two, the independent variable, external religious orientation, predicted discrepancy perfectionism, $\beta=.13, t(374)=2.43, p<.05$. Psychological inflexibility also explained a significant portion of variance in discrepancy perfectionism, $R^{2}=.02, F(1,374)=5.897, p<.05$. In step three, the mediator, psychological inflexibility, had a significant effect on the dependent variable, discrepancy perfectionism, $\beta=-.54, t(373)=-12.14, p<.001$, and the effect of the independent variable, external religious orientation, on the dependent variable, discrepancy perfectionism, was diminished and no longer significant, $\beta=.02$, $t(373)=.34, p>.05$

This successful test of mediation supports the hypothesis that psychological inflexibility accounts for the relationship between external religious orientation and 
discrepancy, or maladaptive, perfectionism. It has already been noted there is a significant correlation between external religious orientation and discrepancy perfectionism. In this correlation, higher levels of external orientation predict higher levels of discrepancy perfectionism. Successful mediation can explain why this correlation exists, in this case because of higher levels of psychological inflexibility. 


\section{CHAPTER V \\ DISCUSSION}

\section{Perfectionism and Religiosity}

An internal or intrinsic religious orientation was characterized as the internalization of religious beliefs that serve as the primary motivation for religious activity. This type of orientation has been characterized as a more positive and adaptive form of religiosity (Allport \& Ross, 1967), and this dimensional model may explain some of the inconsistency in the research that has looked for a relationship between religiosity and negative outcomes. If the research does not account for multiple dimensions, then the expressions of religiosity as related to negative outcomes would likely be inconsistent. For example, there is some indication that religiosity is associated with perfectionism (Ashby \& Huffman, 1999; Richards, Owen, \& Stein, 1993; Williams, 1999), but other research has found little or no correlation (Abramowitz et al., 2004). In this investigation, it was expected that this adaptive form of religiosity would be positively correlated with the adaptive forms of perfectionism (high standards and order) and negatively correlated with maladaptive discrepancy perfectionism. As hypothesized, it was found that an internal religious orientation was positively correlated with high standards perfectionism. Order perfectionism was not significantly correlated with intrinsic religiosity, and discrepancy perfectionism was also not significantly related to internal religiosity, but a trend toward a negative relationship was observed.

The high standards dimension of perfectionism alone is typically designated as 
the positive or adaptive dimension of perfectionism. The order dimension is typically associated with the adaptive high standards, but is not always associated with this factor (Slaney et al., 2001). Religiosity is typically associated with high standards, and these results would suggest that intrinsic religiosity is characterized by high standards that have been internalized and are a source of motivation for religious behavior. The lack of a correlation with the negative dimension of perfectionism (discrepancy) would suggest that these individuals are able to interact flexibly with these high standards. The lack of a significant correlation between internal religiosity and order is also expectable as a preoccupation with order and organization was not implicated in the religiosity literature. These findings are consistent with previous studies that found relationships between intrinsic religiosity and adaptive perfectionism (Ashby \& Huffman, 1999). This study used the same measures of religiosity and perfectionism in a sample of 242 undergraduate college students in the Midwest, with similar results. The consistency of the results in these two studies suggests that the findings of this investigation may be generalized to more heterogeneous religious groups, as the sample in current investigation was predominately from one religious group.

An external or extrinsic religious orientation was characterized by the use of religion for selfish and utilitarian ends such as security, solace, socialization, distraction, or status. This type of orientation is typically characterized as the maladaptive or negative form of religious orientation. In this investigation, it was expected that external religiosity would be positively correlated with all of the dimensions of perfectionism (high standards, order, discrepancy), because of the shared value of high standards between 
perfectionism and religiosity. It was found that an external orientation was significantly correlated with discrepancy perfectionism, but was not significantly correlated with the other dimensions of perfectionism (high standards or order). The correlation between these two variables was small but consistent with the findings from previous investigations that found maladaptive perfectionism was related to problematic spiritual functioning (Thelander, 2002). The discrepancy dimension of perfectionism is an indicator of excessive criticism and doubt about the discrepancy between high standards and actual performance. Certainly, any time an individual sets high standards, there will be a discrepancy between the standards and the actual performance. For individuals with an extrinsic religious orientation, this discrepancy between standards and performance appears to be unacceptable and results in maladaptive perfectionism. This result is consistent with the literature review that suggested a rigid and inflexible style of interaction with high standards. The presence of maladaptive perfectionism is an indicator that the religious activity may be serving an important role or purpose in that individual's life (e.g., security or distraction), and the unmet standards may detract from that goal. It is also possible that individuals with an extrinsic religious orientation may only engage portions of the religious doctrine and not fully understand the role of high standards in religion (e.g., the commandment to be perfect is a gradual and cumulative process).

\section{Psychological Inflexibility}

The idea that psychological inflexibility might mediate the relationship between 
perfectionism and religiosity emerged from research on both constructs. Accounting for the adaptive and maladaptive dimensions helps explain the nature of the relationships and the mediator can explain a possible reason for the relationship. The correlational analyses were consistent with the literature, and again implicated the idea of psychological inflexibility as a possible variable that might account for the relationship between religiosity and perfectionism. This idea was supported by the results.

It was expected that psychological inflexibility would not be correlated with internal religiosity as this inflexibility is typically associated with negative outcomes and intrinsic religiosity is the adaptive form of religiosity. As hypothesized, psychological inflexibility was not significantly related to internal religiosity, but there was a significant negative correlation between psychological inflexibility and external religiosity. It is important to remember that lower scores on the measure of psychological inflexibility indicate higher inflexibility so this negative relationship means that higher levels of inflexibility would predict higher levels of external religiosity. This is consistent with the correlational analyses comparing perfectionism and religiosity as individuals with an external religious orientation were found to display maladaptive discrepancy perfectionism, and thus more rigidity and inflexibility. This suggested an inflexible psychological response to high standards and the inevitable discrepancy between standards and performance.

The relationship between psychological inflexibility and the dimensions of perfectionism was also examined. It was expected that inflexibility would be correlated with the maladaptive discrepancy dimension of perfectionism, but not related to the 
adaptive high standards and order dimensions of perfections. Psychological inflexibility was significantly related to discrepancy perfectionism. Here again, a negative correlation indicated higher levels of inflexibility would predict higher levels of discrepancy perfectionism. This was a large relationship and highlights the nature of discrepancy perfectionism in which unmet standards are unacceptable. This inflexibility is characteristic of the "all or nothing" thinking that is common in perfectionism, and this provides further support for the hypothesis that this inflexibility may be the variable that explains the relationship between high standards, of any type, and maladaptive perfectionism.

\section{Mediation}

A variable is said to function as a mediator if it can account for the relationship between two variables. Psychological inflexibility was implicated in the literature review and the correlational analyses as a possible mediator in the relationship between perfectionism and religiosity. Psychological inflexibility was tested as a mediator between all of the possible combinations of the dimensions of religiosity and perfectionism.

Psychological inflexibility was not found to mediate the relationship between an internal religious orientation and any of the dimensions of perfectionism. This was consistent with the theoretical hypothesis that intrinsic religiosity was more adaptive and could be characterized by a flexible interaction with the high standards of religion.

It was hypothesized that psychological inflexibility would not mediate the 
relationship between external religiosity and high standards or order perfectionism, and this was supported in the mediational analyses. While it was possible that external religiosity might be related to these positive or adaptive dimensions of perfectionism, it was not considered likely that the relationship would be accounted for by a negative psychological variable (i.e., psychological inflexibility). There were no established relationships in the correlational analysis, nullifying the need of a mediator to explain the relationship.

It was hypothesized that psychological inflexibility would mediate the relationship between external religiosity and discrepancy perfectionism, and this was supported in the mediational analysis. External religiosity was found to predict discrepancy perfectionism, but when psychological inflexibility was included in the equation as a mediator, external religiosity was no longer a significant predictor while the mediator was a significant predictor. This suggests that psychological inflexibility can account for the relationship between the two variables. When individuals with an external religious orientation adopt the high standards of a religion, their level of psychological inflexibility will predict the development of maladaptive perfectionism.

This leads to the question of whether or not the inflexibility is a global cause of the extrinsic religious orientation and the maladaptive perfectionism, or if it is possible to have some individual adopt an extrinsic religious orientation and still interact flexibly with the religious standards. This question was not answered directly in this investigation, but the small-to-moderate correlations are suggestive that there are also other variables that could explain the relationship. Additionally, the idea of psychological inflexibility is 
not necessarily a global personality characteristic. For example, individuals with obsessive-compulsive disorder may demonstrate severe inflexibility in their response to contamination obsessions while at the same time they are able to respond flexibly to comorbid conditions or other difficult life events.

\section{Implications of the Results}

The question of the relationship between religiosity and perfectionism is logical given the overlapping concern with high standards. It was suggested in the literature review that it was important to take into account the adaptive and maladaptive dimensions of both constructs to truly understand the relationship. This was apparent as research that identified little or no relationship (see Abramowitz et al., 2004) did not account for the adaptive and maladaptive subdimensions, whereas research that did (see Ashby \& Huffman, 1999) did find a relationship. The results of this investigation are important because they demonstrate the need to account for the adaptive/maladaptive dimensions and clarify the relationship between perfectionism and religiosity, specifically that adaptive religiosity is related to adaptive perfectionism and maladaptive religiosity is related to maladaptive perfectionism.

Both constructs have subdimensions leading to more complex and subtle relationships between the variables. It is therefore important to consider the nature of an individual's religious orientation and dimensions of perfectionism before drawing any conclusions about possible psychopathology. This is important in both theoretical and applied work. In theoretical work, it would be important to look for these dimensions, 
either as designated subscales or in item content when reviewing results. This also suggests caution is in order when discussing any relationship between the constructs. In clinical work, this would have important implications for the etiology, conceptualization, and treatment of perfectionism in a religious context. Perhaps the use of scales that identify these adaptive and maladaptive dimensions of these constructs would be useful in identifying the problem and suggesting possible interventions.

The distinction between adaptive and maladaptive dimensions of both perfectionism and religiosity is an important theme that has emerged from both the literature review and the results of this research. Theoretically, this is similar to the idea of performance enhancing anxiety versus anxiety disorders, or appropriate sadness and grieving versus clinical depression. Emotions or thoughts that are typically evaluated as "negative" (e.g., anxiety, sadness) can lead to negative outcomes, but it is not a definitive relationship. For example, this study has shown that high standards are not inherently bad, but when combined with psychological inflexibility, they can functionally lead to maladaptive perfectionism. This makes the case for a more functional view of personality and psychopathology. In applied work, identifying the functional role of personality in an individual's presentation would be crucial to an accurate understanding of diagnosis and treatment. From this study, it is clear that looking at the functional role of religiosity or perfectionism in an individual's life will help identify any need for, and the type of, intervention.

Perfectionism, particularly maladaptive perfectionism when this has been accounted for in the research, has been linked to numerous problematic outcomes and 
psychopathology including procrastination (Flett et al., 1992), stress (Hewitt \& Flett, 2002), shame and guilt (Fedewa et al., 2005), low self-esteem (Ashby \& Rice, 2002), interpersonal problems (Flett et al., 2001), eating disorders (Goldner et al., 2002), obsessive-compulsive disorder (Shafran \& Mansell, 2001), depression (Hewitt \& Flett, 1991a), social anxiety (Alden et al., 2002), and suicide (Hewitt et al., 1994). The results of this investigation suggest that the relationship between maladaptive religiosity and maladaptive perfectionism can be linked to similar outcomes.

This has important implication in the understanding of religiosity and its possible negative effects. In particular, a major focus in the religiosity literature has been to look for possible negative effects of religiosity on mental health. Religiosity has been associated with both positive and negative psychological outcomes (Wulff, 1996). On the positive side, religiosity has been correlated with healthy psychological adjustment, selfesteem, and low pathology. On the negative side, religiosity has been associated with depression, anxiety, irrational thoughts, and low self-esteem (Judd, 1999). There are also some studies that have found no evidence of a relationship (Bergin, 1983). Recognition of the role of the adaptive and maladaptive dimensions clarifies the inconsistency in the research and also points to the idea of individual differences in how one interacts with a religion. This points to the need for a mediatory to explain why that relationship exists, which in this case, is individual differences in psychological inflexibility.

The identification of psychological inflexibility as a mediator between external religiosity and maladaptive perfectionism is probably the most significant finding of this investigation. In addition to empirical evidence for a relationship between perfectionism 
and religiosity using the adaptive and maladaptive dimensions, a probable cause for that relationship has been established. This provides empirical support for the conclusion from the literature that individual differences would likely account for this relationship, in this case individual differences in psychological inflexibility. This also counters any claims that the high standards of religion can lead to psychopathology. Instead, it is the level of flexibility with which an individual interacts with those high standards. This has important implications for further theoretical work on the relationship between religiosity and perfectionism. Not only should further theoretical work be sure to include analysis of the subdimensions, but mediating variables should be examined as well. There is limited work in the etiology of perfectionism, and this mediational study has provided important insight into the cause of maladaptive perfectionism. The mediational findings may also have important implications for research investigating the relationships between specific environments and any negative outcomes. This is especially true for perfectionism as it has been examined in several different contexts including sports and exercise, school environments, intimate relationships, and professional achievement.

The mediational findings may be most valuable in an applied setting. Clinicians can point to an underlying cause for pathological perfectionism in a religious population. This provides invaluable understanding in the conceptualization of a problem, and provides specific guidance on how to intervene. To address maladaptive perfectionism in a religious population, this study would suggest that increasing psychological flexibility would be the appropriate intervention. Indeed, the construct of psychological inflexibility as defined in this study, is a part of ACT, which is a psychosocial intervention designed 
to target rigid and inflexible interactions with internal events (i.e., thoughts, emotions, and physical sensations; Hayes et al., 1999). ACT has been proven effective at treating several psychological disorders that are characterized by this overall psychological rigidity including anxiety, depression, substance abuse, obsessive-compulsive disorder, and chronic pain (Hayes et al., 2006). The results of this study are thus complementary with the empirical research on ACT. The ACT research would suggest that psychological inflexibility is an important variable in many types of psychopathology, and this investigation confirmed its role as a mediator in a specific psychopathology, maladaptive perfectionism.

\section{Limitations and Future Directions}

While the results of this investigation are significant, it is important to acknowledge the limitations of this research. This study was conducted with a sample of convenience from a college student population. Thus, the results may not be applicable to the general population. Additionally, the majority of the respondents in this study endorsed "Latter-day Saint" (84.3\%) for religious affiliation. As such, these results may need to be replicated with other denominations or more heterogeneous religious samples to demonstrate relevance with the general religious population. The consistency of the correlational results of this study with a similar investigation with a more religiously heterogeneous group (Ashby \& Huffman, 1999) are encouraging, but it would be important to replicate these findings with diverse cultural and age groups. It would also be important to replicate the mediational findings, as these are the first of their kind to be 
demonstrated empirically with perfectionism. Finally, this was a correlational design. The test of mediation does allow for the implication of causation, but the results would be more robust if replicated in a controlled experimental design. A controlled experimental design to test for the effects of psychological inflexibility on maladaptive perfectionism would lead to more robust results and confirm the need to pursue this line of research.

The theoretical implications of this research would suggest continued examination of the role of psychological flexibility in the relationship between religiosity and mental health. There is a history of investigations in this area with controversial results. The use of a third mediating variable may help resolve some of the controversy and provide a better understanding of the psychological impact of religion. Based on this investigation, it is also important to consider both adaptive and maladaptive dimensions of perfectionism when doing any research with these constructs.

The successful application of a mediational design would suggest possible research in both fields of perfectionism and religiosity using this idea. Specifically, the construct of inflexibility could be examined with perfectionism in the other environments found in the literature (e.g., schools, sports, professional achievement). But, it seems clear that this mediational design would help clarify the findings examining the relationship between religiosity and mental health in general.

This investigation also informs further research into the treatment of maladaptive perfectionism. Treatments that address this problem, especially in religious populations, should take into account the role of psychological inflexibility in the development of pathology. Because perfectionism is often found as an underlying feature of other 
psychological disorders (i.e., depression, eating disorders), there is very little empirical research on the treatment of perfectionism because the treatment research is focused on the larger disorder. Treatment research of perfectionism in general would be merited, as well as treatment research that draws on the findings of this investigation. Specifically, the findings of this investigation would suggest the application of ACT for the treatment of maladaptive perfectionism. If an intervention designed to target psychological inflexibility was successful at improving flexibility and reducing maladaptive perfectionism, this would provide additional experimental support for the mediational findings of this investigation. 


\section{REFERENCES}

Abramowitz, J. S., Deacon, B. J., Woods, C. M., \& Tolin, D. F. (2004). Association between protestant religiosity and obsessive-compulsive symptoms and cognitions. Depression and Anxiety, 20, 70-76.

Adler, A. (1956). The neurotic disposition. In H. L. Ansbacher \& R. R. Ansbacher (Eds.), The individual psychology of Alfred Adler (pp. 239-262). New York: Harper.

Alden, L. E., Ryder, A. G., \& Mellings, T. M. B. (2002). Perfectionism in the context of social fears: Toward a two-component model. In G. L. Flett \& P. L. Hewitt (Eds.), Perfectionism: Theory, research, and treatment (pp. 373-391). Washington, DC: American Psychological Association.

Allport, G. W., \& Ross, J. M. (1967). Personal religious orientation and prejudice. Journal of Personality and Social Psychology, 5, 432-443.

American Psychological Association. (2000). Diagnostic and statistical manual of mental disorders ( $4^{\text {th }}$ ed., Text Revision). Washington, DC: Author.

Anshel, M. H., \& Mansouri, H. (2005). Influences of perfectionism on motor performance, affect, and causal attributions in response to critical information feedback. Journal of Sport Behavior, 28, 99-124.

Ashby, J. S., \& Huffman, J. (1999). Religious orientation and multidimensional perfectionism: Relationships and implications. Counseling and Values, 43, 178188.

Ashby, J. S., \& Kottman, T. (1996). Inferiority as a distinction between normal and neurotic perfectionism. Individual Psychology: Journal of Adlerian Theory, Research \& Practice, 52(3), 237-245.

Ashby, J. S., \& Rice, K. G. (2002). Perfectionism, dysfunctional attitudes, and selfesteem: A structural equations analysis. Journal of Counseling \& Development, 80(2), 197-203.

Baron, R. M., \& Kenny, D. A. (1986). The moderator-mediator variable distinction in social psychological research: Conceptual, strategic, and statistical considerations. Journal of Personality and Social Psychology, 51, 1173-1182.

Beck, A. T. (1976). Cognitive therapy and the emotional disorders. New York: International Universities Press. 
Bergin, A. E. (1983). Religiosity and mental health: A critical reevaluation and metaanalysis. Professional Psychology: Research and Practice, 14, 170-184.

Bond, F. W., Hayes, S. C., Baer, R. A., Carpenter, K. M., Orcutt, H. K., Waltz, T., \& Zettle, R. D. (2009) Preliminary psychometric properties of the Acceptance and Action Questionnaire - II: A revised measure of psychological flexibility and acceptance. Manuscript submitted for publication.

Branfman, T., \& Bergler, E. (1955). Psychology of perfectionism. American Imago, 12(9), 9-15.

Burns, D. D. (1980). The perfectionist's script for self-defeat. Psychology Today, 13, 3452.

Donahue, M. J. (1985). Intrinsic and extrinsic religiousness: Review and meta-analysis. Journal of Personality and Social Psychology, 48, 400-419.

Ellis, A. (1962). Reason and emotion in psychotherapy. New York: Stuart.

Enns, M. W., \& Cox, B. J. (2002). The nature and assessment of perfectionism: A critical analysis. In G.L. Flett \& P.L. Hewitt (Eds.), Perfectionism: Theory, research, and treatment (pp. 33-62). Washington, DC: American Psychological Association.

Enns, M. W., Cox, B. J., Sareen, J., \& Freeman, P. (2001). Adaptive and maladaptive perfectionism in medical students: A longitudinal investigation. Medical Education, 35, 1034-1042.

Erikson, E. H. (1966). Ontogeny of ritualization in man. Philosophical Transactions of the Royal Society of London: Series B, Biological Sciences, 251, 337-349.

Fedewa, B. A., Burns, L. R., \& Gomez, A. A. (2005). Positive and negative perfectionism and the shame/guilt distinction: Adaptive and maladaptive characteristics. Personality and Individual Differences, 38, 1609-1619.

Flett, G. L., Blankstein, K. R., Hewitt, P. L., \& Koledin, S. (1992). Components of perfectionism and procrastination in college students. Social Behavior and Personality, 20(2), 85-94.

Flett, G. L., \& Hewitt, P. L. (2005). The perils of perfectionism in sports and exercise. Current Directions in Psychological Science, 14(1), 14-18. 
Flett, G. L., \& Hewitt, P. L. (2006). Positive versus negative perfectionism in psychopathology: A comment on Slade and Owen's dual process model. Behavior Modification, 30, 472-495.

Flett, G. L., Hewitt, P. L., \& Hallett, C. J. (1995). Perfectionism and job stress in teachers. Canadian Journal of School Psychology, 11, 32-42.

Flett, G. L., Hewitt, P. L., Shapiro, B., \& Rayman, J. (2001). Perfectionism, beliefs, and adjustment in dating relationships. Current Psychology: Development, Learning, Personality, Social, 20, 289-311.

Freud, S. (1959). Inhibitions, symptoms, and anxiety. In J. Strachey (Ed. and Trans.), The standard edition of the complete psychological works of Sigmund Freud (Vol. 20, pp. 77-175). London: Hogarth Press. (Original work published 1923)

Freud, S. (1961). The future of an illusion. New York: Norton. (Original work published in 1927)

Frost, R. O., \& DiBartolo, P. M. (2002). Perfectionism, anxiety, and obsessivecompulsive disorder. In G. L. Flett \& P. L. Hewitt (Eds.), Perfectionism: Theory, research, and treatment (pp. 341-371). Washington, DC: American Psychological Association.

Frost, R. O., Heimberg, R. G., Holt, C. S., Mattia, J. I., \& Neubauer, A. L. (1993). A comparison of two measures of perfectionism. Personality and Individual Differences, 14, 119-126.

Frost, R. O., Marten, P., Lahart, C., \& Rosenblate, R. (1990). The dimensions of perfectionism. Cognitive Therapy and Research, 14, 449-468.

Frost, R. O., \& Steketee, G. (1997). Perfectionism in obsessive-compulsive disorder patients. Behaviour Research and Therapy, 35, 291-296.

Gilman, R., \& Ashby, J. S. (2003). Multidimensional perfectionism in a sample of middle school students: An exploratory investigation. Psychology in the Schools, 40, 677689.

Goldner, E. M., Cockell, S. J., \& Srikameswaran, S. (2002). Perfectionism and eating disorders. In G. L. Flett \& P. L. Hewitt (Eds.), Perfectionism: Theory, research, and treatment (pp. 319-340). Washington, DC: American Psychological Association.

Gorsuch, R. L., \& Venable, G. D. (1983). Development and validation of an "age universal” I-E scale. Journal for the Scientific Study of Religion, 22, 181-187. 
Gotwals, J. K., Dunn, J. G. H., \& Wayment, H. A. (2003). An examination of perfectionism and self-esteem in intercollegiate athletes. Journal of Sports Behavior, 26, 17-38.

Haase, A. M., Prapavessis, H., \& Owens, R. G. (1999). Perfectionism and eating attitudes in competitive rowers: Moderating effects of body mass, weight classification and gender. Psychology and Health, 14, 643-657.

Hamachek, D. E. (1978). Psychodynamics of normal and neurotic perfectionism. Psychology, 15, 27-33.

Hayes, S. C., Luoma, J. B., Bond, F. W., Masuda, A., \& Lillis, J. (2006). Acceptance and Commitment Therapy: Model processes and outcomes. Behaviour Research and Therapy, 44, 1-25.

Hayes, S. C., Masuda, A., Bissett, R., Luoma, J., \& Guerrero, L. F. (2004). DBT, FAP, and ACT: How empirically oriented are the new behavior therapy technologies? Behavior Therapy, 35, 35-54.

Hayes, S. C., Strosahl, K. D., \& Wilson, K. G. (1999). Acceptance and commitment therapy: An experiential approach to behavior change. New York: Guilford.

Hayes, S. C., Strosahl, K., Wilson, K. G., Bissett, R. T., Pistorello, J., Toarmino, D., Polusny, M. A., Dykstra, T. A.,...McCurry, S. M. (2004). Measuring experiential avoidance: A preliminary test of a working model. The Psychological Record, 54(4), 553-578.

Heise, R. G., \& Steitz, J. A. (1991). Religious perfectionism versus spiritual growth. Counseling and Values, 36, 11-18.

Henning, K., Ey, S., \& Shaw, D. (1998). Perfectionism, the imposter phenomenon and psychological adjustment in medical, dental, nursing and pharmacy students. Medical Education, 32, 456-464.

Hewitt, P. L., \& Flett, G. L. (1991a). Dimensions of perfectionism in unipolar depression. Journal of Abnormal Psychology, 100, 98-101.

Hewitt, P. L., \& Flett, G. L. (1991b). Perfectionism in the self and social contexts: Conceptualization, assessment, and association with psychopathology. Journal of Personality and Social Psychology, 60, 456-470. 
Hewitt, P. L., \& Flett, G. L. (2002). Perfectionism and stress processes in psychopathology. In G. L. Flett \& P. L. Hewitt (Eds.), Perfectionism: Theory, research, and treatment (pp. 255-284). Washington, DC: American Psychological Association.

Hewitt, P. L., Flett, G. L., \& Weber, C. (1994). Dimensions of perfectionism and suicide ideation. Cognitive Therapy and Research, 18, 439-460.

Hill, P. C., \& Hood, R. W. (1999). Measures of religiosity. Birmingham, AL: Religious Education Press.

Hollender, M. H. (1965). Perfectionism. Comprehensive Psychiatry, 6(2), 94-103.

Hood, R. W., \& Belzen, J. A. (2005). Research methods in the psychology of religion. In R. F. Paloutzian \& C. L. Park (Eds.), Handbook of the psychology of religion and spirituality (pp. 62-79). New York: Guilford.

Horney, K. (1950). Neurosis and human growth. New York: Norton.

Hunt, R. A., \& King, M. (1971). The intrinsic-extrinsic concept: A review and evaluation. Journal for the Scientific Study of Religion, 10, 339-356.

James, W. (1985). The varieties of religious experience. Cambridge, MA: Harvard University Press. (Original work published 1902)

Johnson, D. P. \& Slaney, R. B. (1996). Perfectionism: Scale development and a study of perfectionistic clients in counseling. Journal of College Student Development, 37, $29-41$.

Judd, D. K. (1999). Religious affiliation and mental health. In D. K. Judd (Ed.), Religion, mental health and the Latter-day Saints (pp. 245-279). Provo, UT: Religious Studies Center.

Jung, C. G. (1938). Psychology and religion. London: Yale University Press.

Juster, H. R., Heimberg, R. G., Frost, R. O., Holt, C. S., Mattia, J. I., \& Faccenda, K. (1996). Social phobia and perfectionism. Personality and Individual Differences, 21, 403-410.

Kirkpatrick, L. A., \& Hood, R. W. (1990). Intrinsic-extrinsic religious orientation: The boon or bane of contemporary psychology of religion? Journal for the Scientific Study of Religion, 29, 442-462. 
Klibert, J. J., Langhinrichsen-Rohling, J., \& Saito, M. (2005). Adaptive and maladaptive aspects of self-oriented versus socially prescribed perfectionism. Journal of College Student Development, 46, 141-156.

Lundh, L., Broman, J., Hetta, J., \& Saboonchi, F. (1994). Perfectionism and insomnia. Scandinavian Journal of Behaviour Therapy, 23, 3-18.

MacKenna, C. (2007). The dream of perfection. British Journal of Psychotherapy, 23, 247-266.

McCandless, J. B. (1991). The church confronting adult depression: A challenge. Counseling and Values, 35, 104-113.

Mitchelson, J., \& Burns, L. R. (1998). Career mothers and perfectionism: Stress at work and at home. Personality and Individual Differences, 25, 477-485.

Mobley, M., Slaney, R. B., \& Rice, K. G. (2005). Cultural validity of the Almost Perfect Scale-Revised for African American college students. Journal of Counseling Psychology, 52, 629-639.

Mor, S., Day, H. I., Flett, G. L., \& Hewitt, P. L. (1995). Perfectionism, control, and components of performance anxiety in professional artists. Cognitive Therapy and Research, 19, 207-225.

Nelson, R. M. (1995). Perfection pending. Ensign, 25, 86-88.

Olatunji, B. O., Forsyth, J. P., \& Feldner, M. T. (2007). Implications of emotion regulation for the shift from normative fear-relevant learning to anxiety-related psychopathology. American Psychologist, 62(3), 257-259.

Pacht, A. R. (1984). Reflections on perfection. American Psychologist, 39, 386-390.

Parker, W. D. (2002). Perfectionism and adjustment in gifted children. In G. L. Flett \& P. L. Hewitt (Eds.), Perfectionism: Theory, research, and treatment (pp. 133-148). Washington, DC: American Psychological Association.

Parker, W. D., \& Adkins, K. K. (1995). A psychometric examination of the Multidimensional Perfectionism Scale. Journal of psychopathology and behavioral assessment, 17, 323-334.

Rice, K. G., \& Dellwo, J. P. (2002). Perfectionism and self-development: Implications for college adjustment. Journal of Counseling and Development, 80, 188-196. 
Rice, K. G., \& Preusser, K. J. (2002). The Adaptive/Maladaptive Perfectionism Scale. Measurement and Evaluation in Counseling and Development, 34, 210-222.

Richards, P. S., Owen, L., \& Stein, S. (1993). A religiously oriented group counseling intervention for self-defeating perfectionism: A pilot study. Counseling and Values, 37, 96-104.

Saboonchi, F., \& Lundh, L. (2003). Perfectionism, anger, somatic health, and positive affect. Personality and Individual Differences, 35, 1585-1599.

Shafran, R., \& Mansell, W. (2001). Perfectionism and psychopathology: A review of research and treatment. Clinical Psychology Review, 21, 879-906.

Shea, A. J., Slaney, R. B., \& Rice, K. G. (2006). Perfectionism in intimate relationships: The Dyadic Almost Perfect Scale. Measurement and Evaluation in Counseling and Development, 39, 107-125.

Sica, C., Novara, C., \& Sanavio, E. (2002). Religiousness and obsessive-compulsive cognitions and symptoms in an Italian population. Behaviour Research and Therapy, 40, 813-823.

Skinner, B. F. (1953). Science and human behavior. New York: MacMillan.

Slade, P. D., \& Owens, R. G. (1998). A dual process model of perfectionism based on reinforcement theory. Behavior Modification, 22, 372-390.

Slaney, R. B., \& Ashby, J. S. (1996). Perfectionists: Study of a criterion group. Journal of Counseling and Development, 74, 393-398.

Slaney, R. B., Rice, K. G., \& Ashby, J. S. (2002). A programmatic approach to measuring perfectionism: The almost perfect scales. In G. L. Flett \& P. L. Hewitt (Eds.), Perfectionism: Theory, research, and treatment (pp. 63-88). Washington, DC: American Psychological Association.

Slaney, R. B., Rice, K. G., Mobley, M., Trippi, J., \& Ashby, J. S. (2001). The revised Almost Perfect Scale. Measurement and Evaluation in Counseling and Development, 34, 130-145.

Sorotzkin, B. (1998). Understanding and treating perfectionism in religious adolescents. Psychotherapy, 35, 87-95.

Stoeber, J., \& Otto, K. (2006). Positive conceptions of perfectionism: Approaches, evidence, challenges. Personality and Social Psychology Review, 10, 295-319. 
Terry-Short, L. A., Owens, R. G., Slade, P. D., \& Dewey, M. E. (1995). Positive and negative perfectionism. Personality and Individual Differences, 18, 663-668.

Thelander, S. E. (2002). The relationship of adaptive and maladaptive dimensions of perfectionism to qualities of spiritual functioning (Doctoral dissertation).

Dissertation Abstracts International Section B: The Sciences and Engineering, 63, 11B. (UMI No. 3071238)

Timpe, R. L. (1989). Perfectionism: Positive possibility or personal pathology? Journal of Psychology and Christianity, 8, 23-34.

Williams, M. (1999). Family attitudes and perfectionism as related to depression in Latter-day Saint and Protestant women. In D. K. Judd (Ed.), Religion, mental health, and the Latter-day Saints (pp. 47-66). Provo, UT: Religious Studies Center.

Wilson, K.G., \& Murrell, A.R. (2004). Values work in acceptance and commitment therapy. In S. C. Hayes, V. M. Follette, \& M. M. Linehan (Eds.) Mindfulness and Acceptance (pp. 120-151). New York: Guilford.

Wulff, D. M. (1996). The psychology of religion: An overview. In E. Shafranske (Ed.), Religion and the clinical practice of psychology (pp. 43-70). Washington, DC: American Psychological Association.

Zinnbauer, B. J., \& Pargament, K. I. (2005). Religiousness and spirituality. In R. F. Paloutzian \& C. L. Park (Eds.), Handbook of the psychology of religion and spirituality (pp. 21-42). New York: Guilford.

Zohar, A. H., Goldman, E., Calamary, R., \& Mashiah, M. (2005). Religiosity and obsessive-compulsive behavior in Israeli Jews. Behaviour Research and Therapy, 43, 857-868. 
APPENDICES 
Appendix A

Measures 


\section{Demographics}

1. What is your sex?

Female, Male

2. What is your age?

3. What is your marital status?

Single, Married, Divorced, Separated, Remarried, Widowed/Widower

4. How many years of post high school education have you completed?

5. What is your ethnicity/race?

African American, Asian American, Caucasian, Hispanic, Native American, Other

6. What is your current religious affiliation?

Baptist, Catholic, Jewish, Latter-day Saint, Lutheran, Methodist, Unitarian, No Affiliation, Other

7. What religion(s) have you been affiliated with in the past?

Baptist, Catholic, Jewish, Latter-day Saint, Lutheran, Methodist, Unitarian, No Affiliation, Other

8. How often do you participate in organized religious activities?

Never, A Few Times a Year, Monthly, A Few Times a Month, Weekly, A Few Times a Week, and Daily.

9. Please rate how important religion is to you?

Not at All Important, Somewhat Important, Neutral, Important, Very Important 
Almost Perfect Scale-Revised

Answer the following questions using the following scale to describe your degree of agreement with each item:

1. Strongly Disagree

2. Disagree

3. Slightly Disagree

4. Neutral

5. Slightly Agree

6. Agree

7. Strongly Agree

1 (S). I have high standards for my performance at work or at school.

2 (O). I I am an orderly person.

3 (D). I I often feel frustrated because I can't meet my goals.

$4(\mathrm{O})$. Neatness is important to me.

5 (S). If you don't expect much out of yourself you will never succeed.

6 (D). My best just never seems to be good enough for me.

7 (O). I think things should be put away in their place.

8 (S). I have high expectations for myself.

9 (D). I rarely live up to my high standards.

$10(\mathrm{O})$. I like to always be organized and disciplined.

11 (D). Doing my best never seems to be enough.

12 (S). I set very high standards for myself.

13 (D). I am never satisfied with my accomplishments.

14 (S). I expect the best from myself.

15 (D). I often worry about not measuring up to my own expectations.

16 (D). My performance rarely measures up to my standards.

17 (D). I am not satisfied even when I know I have done my best.

18 (S). I try to do my best at everything I do.

19 (D). I am seldom able to meet my own high standards for performance.

20 (D). I am hardly ever satisfied with my performance.

21 (D). I hardly ever feel that what I've done is good enough.

22 (S). I have a strong need to strive for excellence.

23 (D). I often feel disappointment after completing a task because I know I could have done better.

Discrepancy: 3, 6, 9, 11, 13, 15, 16, 17, 19, 20, 21, 23

High Standards: 1, 5, 8, 12, 14, 18, 22

Order: $2,4,7,10$ 
Age Universal Religious Orientation Scale

Using the scale provided, determine to what degree you agree or disagree with each of the following statements.

$\begin{array}{lllll}1 & 2 & 3 & 4 & 5\end{array}$

Strongly Disagree Strongly Agree

I enjoy reading about my religion.

I go to church because it helps me to make friends.

It doesn't much matter what I believe so long as I am good.

Sometimes I have to ignore my religious beliefs because of what people might think of me.

It is important to me to spend time in private thought and prayer.

I would prefer to go to church:

(1) a few times a year or less

(2) once every month or two

(3) two or three times a month

(4) about once a week

(5) more than once a week

I have often had a strong sense of God's presence

I pray mainly to gain relief and protection

I try to live all my life according to my religious beliefs

What religion offers me most is comfort in times of trouble and sorrow

My religion is important because it answers many questions about the meaning of

life

I would rather join a Bible study group than a church social group

Prayer is for peace and happiness

Although I am religious, I don't let it affect my daily life

I go to church mostly to spend time with my friends

My whole approach to life is based on my religion

I go to church mainly because I enjoy seeing people I know there

I pray mainly because I have been taught to pray

Prayers I say when I'm alone are as important to me as those I say in church

Although I believe in my religion, many other things are more important in life 
Acceptance and Action Questionnaire-II

Below you will find a list of statements. Please rate how true each statement is for you according to the following scale:

1. Never true

2. Very seldom true

3. Seldom true

4. Sometimes true

5. Frequently true

6. Almost always true

7. Always true

1. Its $\mathrm{OK}$ if I remember something unpleasant.

2. My painful experiences and memories make it difficult for me to live a life that I would value. ( $R$ )

3. I'm afraid of my feelings. (R)

4. I worry about not being able to control my worries and feelings. (R)

5. My painful memories prevent me from having a fulfilling life. (R)

6. I am in control of my life.

7. Emotions cause problems in my life. (R)

8. It seems like most people are handling their lives better than I am. (R)

9. Worries get in the way of my success. (R)

10. My thoughts and feelings do not get in the way of how I want to live my life.

(R) Reverse Scoring 
Appendix B

Recruiting Materials 


\section{Research Opportunity}

The Psychology Department at Utah State University is seeking individuals to complete a survey of personality and religion. The survey will take approximately 30 minutes and is completed online at:

$$
\text { websurvey.usu.edu/personality }
$$

This link will take you to an informed consent. If you agree to participate, you can proceed with the survey. If you do not agree to participate, please close your internet browser
All responses will be anonymous (no identifying information will be connected to the responses). If you are in a psychology course that offers credit or extra credit for research participation, you can enter your name and course information to receive credit. If you have questions please contact Scott Bates, Ph.D. at (435) 797-2975 (scott.bates@usu.edu) or Jesse Crosby at (435) 797-8303 (jesse.crosby@aggiemail.usu.edu). 
Appendix C

Informed Consent 


\section{Informed Consent}

\section{Personality and Religion}

Introduction/Purpose: Dr. Scott Bates and Jesse Crosby from the Department of Psychology at USU are inviting you to participate in a research study of personality and religion. This study is being done at USU with a total of approximately 200 participants, age 18 years and older. The purpose of this study is to measure personality characteristics in a religious population.

Procedures: You will be asked to complete approximately 100 survey questions that ask about your behaviors, thoughts, and feelings. The questions are short and can be answered quickly. It may take about 30 minutes to complete the questions. The entire survey is completed online and can be done at a time and/or location of your choosing. Your responses will be anonymous and any identifying information that you provide will not be linked to your responses. You may stop the survey at any time and your data will not be saved. You may also skip any questions that you do not want to answer.

When you finish the survey you will be given the opportunity to enter your name and course information if you are taking a class that offers credit or extra credit for research participation to receive credit for completing the survey. This information will not be linked to your responses.

Risks/Benefits: Your participation in this study is considered minimal risk. However, there is a possibility that you may feel uncomfortable answering some of the questions about private thoughts, feelings, or behaviors. Everything possible has been done to minimize this risk.

The online survey is being hosted by a secure server that maintains high standards of confidentiality and data security. All information that you provide will remain completely confidential and there is no way to link your name or your computer to the responses you provide. It is safe to answer honestly.

You will be given the opportunity to enter your contact and class information if you want to receive course credit for participating. This information will be stored separately from your responses and, again, there is no way to link your contact information to the responses you provide.

If you need any assistance with any possible distress related to your participation, you may contact the USU Counseling Center located in the Taggart Student Center Room 306 (435) 797-1012.

You may not receive any direct benefits from participating in this survey, but the information you provide will inform the development of effective treatments for problematic behaviors, thoughts, and feelings.

Explanation and Offer to Answer Questions: You may contact the researchers at any 
time with questions about the study. The contact information is listed below.

Voluntary Participation and Withdrawal from Study: Participation is voluntary. You may discontinue the study at any time for any reason without consequence.

Confidentiality: Research records will be kept confidential, consistent with federal and state regulations. Only the researchers will have access to the records which will be kept on secure computers in locked facilities. Your identifying information, if you choose to provide it at the end of the survey, will not be linked to your responses.

IRB Approval Statement: The Institutional Review Board (IRB) for the protection of human participants at USU has approved this research study. If you have any pertinent questions or concerns about your rights or think the research may have harmed you, you may contact the IRB Administrator at (435) 797-0567. If you have a concern or complaint about the research and you would like to contact someone other than the research team, you may contact the IRB Administrator to obtain information or to offer input.

Researcher's Statement: By continuing this survey, you agree that you have read this consent form, and that you understand the nature and purpose of the research. You also signify that you understand the possible risks and benefits associated with participating in this study, and that you have been provided with the necessary contact information should you have any questions.

Scott C. Bates, Ph.D.

Principal Investigator

Scott.bates@usu.edu

(435) 797-2975

Jesse M. Crosby

Student Researcher

jesse.crosby@aggiemail.usu.edu

(435) 797-8303

["I Agree" link to continue with survey]

Please print this page for your records. 